\title{
Effectiveness of struvite precipitation and ammonia stripping for recovery of phosphorus and nitrogen from anaerobic digestate: a systematic review
}

\author{
Dag Lorick 1* $^{*}$, Biljana Macura ${ }^{1}$, Marcus Ahlström², Anders Grimvall ${ }^{3}$ and Robin Harder ${ }^{4}$
}

\begin{abstract}
Background: A regular supply of nutrients such as nitrogen and phosphorus to agriculture is needed for global food security, and increased recycling of nutrients back to agriculture from organic waste streams is necessary for increased rural-urban sustainability. Anaerobic digestion of sewage sludge and agricultural wastes is widely applied to stabilize the substrate and capture some of its energetic value via biogas production. Anaerobic digestate is a concentrated source of nutrients to which nutrient recovery technologies can be applied. By combining anaerobic digestion and nutrient recovery technologies on the digestate, both energy and nutrient recovery can be achieved. Two promising technologies that could increase nutrient recycling from different types of wastewater are struvite precipitation and ammonia stripping. This review examined the effectiveness of these ecotechnologies for the recovery of nitrogen and phosphorus from anaerobic digestate with the aim of reducing the impact of waste on the environment.
\end{abstract}

Methods: We searched for academic and grey literature published after 2013. Searches were performed in 5 bibliographic databases in English, in the search engine Google Scholar in English, Swedish, Finnish and Polish, and across a range of organisational websites in English, Swedish, Finnish and Polish. Eligibility screening was conducted at two levels: 'title and abstract' and 'full text'. Included eligible studies were subject to a critical appraisal that assessed external and internal study validity. We extracted information on study characteristics, intervention, comparators, effect modifiers, and measured outcomes. Data synthesis included narrative synthesis of each study of sufficient validity. We performed quantitative synthesis on a subset of studies.

Review findings: The review included 30 studies on struvite precipitation and 8 studies on ammonia stripping. Both $\mathrm{pH}$ and $\mathrm{Mg}: \mathrm{PO}_{4}$ ratio were found to have a clear influence on the effectiveness of struvite precipitation process (and thus nutrient removal rates). The response to $\mathrm{pH}$ was found to be non-linear, resembling a bell curve with a maximum around $\mathrm{pH}$ 9.5. $\mathrm{Mg}_{\mathrm{PO}} \mathrm{P}_{4}$ ratio was found to have a positive effect on removal up to a ratio as high as 4:1. However, it should be noted that high removal efficiencies were sometimes achieved at a ratio as low as 1:1 as well. Although the effects of $\mathrm{pH}$ and $\mathrm{Mg}: \mathrm{PO}_{4}$ ratio were clear, the model developed could not accurately predict removal based on these two parameters alone. Studies on ammonia stripping were relatively heterogeneous. Due to the small size of the evidence base, and the heterogeneity between studies, no conclusions are presented regarding the influence of different process parameters on the outcome of ammonia stripping.

\footnotetext{
*Correspondence: daglorick@gmail.com

1 Stockholm Environment Institute, Linnégatan 87D, Stockholm, Sweden

Full list of author information is available at the end of the article
}

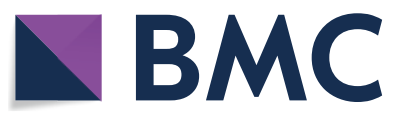

(c) The Author(s) 2020. This article is licensed under a Creative Commons Attribution 4.0 International License, which permits use, sharing, adaptation, distribution and reproduction in any medium or format, as long as you give appropriate credit to the original author(s) and the source, provide a link to the Creative Commons licence, and indicate if changes were made. The images or other third party material in this article are included in the article's Creative Commons licence, unless indicated otherwise in a credit line to the material. If material is not included in the article's Creative Commons licence and your intended use is not permitted by statutory regulation or exceeds the permitted use, you will need to obtain permission directly from the copyright holder. To view a copy of this licence, visit http://creativeco mmons.org/licenses/by/4.0/. The Creative Commons Public Domain Dedication waiver (http://creativecommons.org/publicdomain/ zero/1.0/) applies to the data made available in this article, unless otherwise stated in a credit line to the data. 
Conclusions: In conclusion, when performed under the right conditions (i.e. $\mathrm{pH}$ around 9.5 and $\mathrm{Mg}: \mathrm{PO}_{4}$ ratio of at least 1:1), available evidence suggests that struvite precipitation is an effective technology for the recovery of nutrients from the liquid phase of anaerobic digestate. The evidence base is limited for ammonia stripping. We provided suggestions of which data to report in future studies.

Keywords: Circular economy, Wastewater treatment, Manure management

\section{Background}

Global food security depends on a regular supply of nutrients such as nitrogen $(\mathrm{N})$ and phosphorus $(\mathrm{P})[1]$. The last century has seen a large-scale shift towards synthetic fertilizers: the $\mathrm{N}$ in agricultural fertilizer is now largely synthesized through the energy-demanding Haber-Bosch process [2], while much of the $\mathrm{P}$ is extracted from finite mineral reserves [3]. Overutilization of these convenient sources of nutrients has not only led to eutrophication, it has also raised concerns regarding future nutrient supply and food security [4]. Prior to the advent of synthetic fertilizers, animal manure and human excreta were the dominant nutrient sources for crop production. Animal manure still plays a key role: in the EU27 for instance, spreading manure on agricultural land constituted approximately $53 \%$ of the P and $33 \%$ of the $\mathrm{N}$ applied annually to agricultural soils in 2005 [5]. However, large-scale industrial animal production as well as spatial segregation of crop-intensive and livestock-intensive areas leads to uneven spatial distribution of manure, creating nutrient-deficient areas on the one hand and nutrient hot-spots on the other [6-8]. Finding cost-effective manure processing technologies that facilitate the transfer of nutrients between these areas and produce safe and stable fertilisers from organic waste streams is a fundamental quest for sustainable agricultural production [9].

The nutrients contained in domestic wastewater could substantially contribute to global nutrient demand if they are successfully recycled [10]. However, wastewater treatment has traditionally focused on protecting receiving water bodies against eutrophication, through the removal of organic matter, $\mathrm{N}$ and $\mathrm{P}$ from the effluent, rather than on nutrient recovery per se. Some nutrient reuse (primarily P) from domestic wastewater has been achieved for many decades through the application of sewage sludge to agricultural fields. However, a large share of the sewage sludge produced in the world is currently either landfilled or used in ways that does not contribute to efficient use of nutrients for food security [11]. The P content in sludge depends on the $\mathrm{P}$ removal processes applied at the WWTP, where P removal from wastewater into the sludge can be achieved by different chemical precipitation or biological removal processes [12]. The recovery rate of $\mathrm{N}$ through sludge application is low compared to that of $\mathrm{P}$, since most $\mathrm{N}$ is either removed by denitrification or remains in the treated wastewater at conventional WWTPs [13]. The suitability of sludge as a fertiliser in agriculture is debated in many countries due to contaminants that can be found in it. In addition, WWTPs are typically not located close to the arable land where sludge from wastewater processing could be applied [7], which increases the difficulty and costs of transporting it.

Complementary nutrient recovery could decrease the need for mineral $\mathrm{P}$ and $\mathrm{N}$ fertilisers, reducing the pressure on respective biogeochemical cycles $[14,15]$. Anaerobic digestion of sewage sludge, blackwater, manure and other agricultural residual streams is widely applied to produce biogas, which can be a source of renewable energy. Dewatering of the digestate (the organic material resulting from digestion), often applied to reduce its weight, results in a liquid and a solid phase. The liquid phase of anaerobic digestate is a source of nutrients, such as $\mathrm{N}$ and $\mathrm{P}$, to which nutrient recovery technologies is often applied. The catch is that the liquid phase of digestate only contains a portion of the total nutrient influx, which limits the total recovery potential. Nevertheless, by combining anaerobic digestion and nutrient recovery technologies, both energy and nutrient recovery can be achieved.

There are many technological solutions for nutrient recovery from organic waste streams available on the market, several of which are suitable to apply to the liquid phase of digestate. Two of these are struvite precipitation and ammonia stripping. These two technologies for $\mathrm{P}$ and $\mathrm{N}$ recovery were identified in systematic maps of technologies for recovering nutrients and carbon from domestic wastewater $[16,17]$ and agricultural waste streams [18], where struvite precipitation was one of the most represented technologies.

Struvite precipitation is a technology that is used mainly for $\mathrm{P}$ recovery. Struvite is a crystalline mineral composed of equimolar concentrations of magnesium $(\mathrm{Mg})$, ammonium $\left(\mathrm{NH}_{4}\right)$ and phosphate $\left(\mathrm{PO}_{4}\right)$ with the chemical formula $\mathrm{MgNH}_{4} \mathrm{PO}_{4}{ }^{*} 6 \mathrm{H}_{2} \mathrm{O}$. The struvite precipitation process depends on several parameters, perhaps most notably $\mathrm{pH}$ and the molar ratio of $\mathrm{NH}_{4}, \mathrm{PO}_{4}$ and $\mathrm{Mg}$ in the liquid. A simplified precipitation process is depicted in Fig. 1. Although wastewater typically includes some $\mathrm{Mg}$, the ratio of $\mathrm{Mg}$ to $\mathrm{PO}_{4}$ and $\mathrm{NH}_{4}$ in 


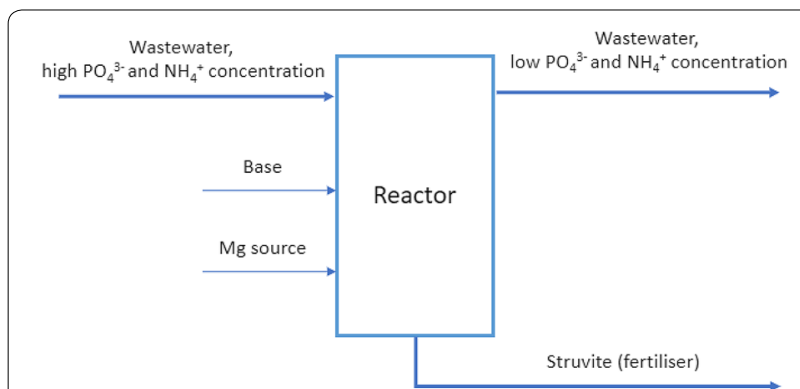

Fig. 1 Simplified struvite precipitation process ( Source: own elaboration)

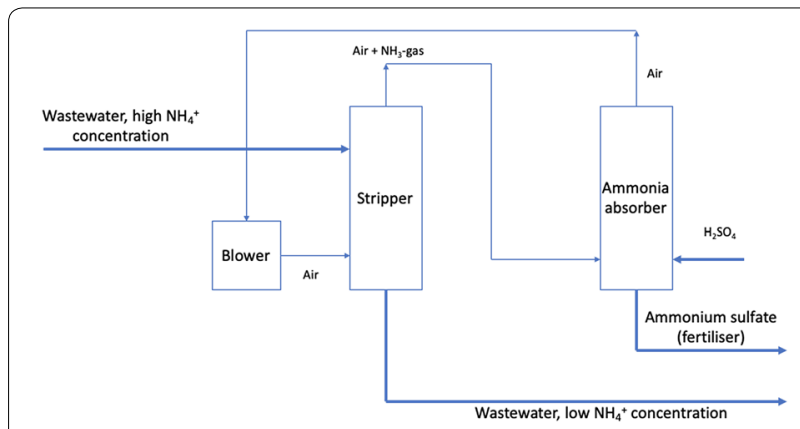

Fig. 2 Simplified ammonia stripping process ( Source: own elaboration)

the stream must often be improved through $\mathrm{Mg}$ additions to achieve efficient struvite precipitation from wastewater rich in $\mathrm{PO}_{4}$ and $\mathrm{NH}_{4}$. Provided an excess in $\mathrm{Mg}$, the concentration of either $\mathrm{PO}_{4}$ or $\mathrm{NH}_{4}$ in the stream will limit the reaction (depending on whether $\mathrm{PO}_{4}$ or $\mathrm{NH}_{4}$ has the lower concentration). Struvite is an effective slow-release fertiliser with a relatively low content of contaminants, which can replace fertilisers produced from phosphate rock [19]. The value of struvite as fertiliser has only recently been understood and it is now the focus of increasing research attention [20].

Ammonia stripping is applied to liquids containing high concentrations of ammonia [21, 22]. Figure 2 shows a simplified ammonia stripping process. High temperature and $\mathrm{pH}$ increase the efficiency of ammonia stripping, since this leads to a larger fraction of $\mathrm{N}$ being present as gaseous ammonia. Other parameters that may influence the effectiveness of the process include liquid to gas flow ratio and reactor configuration (i.e. counterflow or cross-current). The stripped ammonia gas is recovered by absorption to an acid, commonly sulphuric acid. The resulting product is a low $\mathrm{pH}$ ammonium sulphate, used as a fertiliser recommended for use on soils with alkaline or neutral reaction [22].

Although there are some relevant reviews on the topic $[6,23,24]$, to our knowledge, no systematic reviews of the effectiveness of struvite precipitation or ammonia stripping for reuse of nutrients from anaerobic digestate have been conducted.

\section{Stakeholder engagement}

The topic for this review was initially proposed by the research funder BONUS (https://www.bonusporta l.org/). The scope of the project was then refined through expert discussions as part of the process of drafting an application in response to the call by the research funder. The scope and the search strategy were further refined by a stakeholder group consisting of the broader BONUS RETURN project consortium members (see https://www.bonusreturn.com/), local stakeholders from the three BONUS RETURN case study areas in Finland, Poland and Sweden, as well as external experts from these countries, which explains the Baltic Sea basin focus.

\section{Objective of the review}

The primary review question for this review was as follows:

\section{How effective are struvite precipitation and ammonia stripping for the recovery of phosphorus and nitrogen from the liquid phase of anaerobic digestate?}

This review focused on struvite precipitation and ammonia stripping currently developed and applied globally. Specifically, we have chosen to investigate $\mathrm{P}$ (and to some extent $\mathrm{N}$ ) recovery through struvite precipitation and $\mathrm{N}$ recovery through ammonia stripping. The liquid phase of anaerobic digestate was chosen as nutrient source, since it is commonly produced in the current management of both manure and municipal wastewater.

The review question components are as follows:

- Population(s) Liquid phase of anaerobic digestate from agricultural residuals and domestic wastewater (including blackwater) produced globally.

- Intervention(s) Struvite precipitation and ammonia stripping undertaken for the purposes of recovering $\mathrm{N}$ and $\mathrm{P}$ from the liquid phase of anaerobic digestate.

- Comparator(s) Inflow concentrations served as a control. 
- Outcome(s) Recovery of N (total N, ammonium and/ or ammonia) and P (total P, phosphate) expressed as a percentage of the nutrient content of the digestate.

\section{Methods}

The review followed the Collaboration for Environmental Evidence Guidelines and Standards for Evidence Synthesis in Environmental Management [25] and conformed to ROSES reporting standards [26] (see Additional file 1). It was designed according to the protocol published in early 2019 [27], with one alteration. In the protocol we describe a combined review of current research regarding the technical processes of struvite precipitation and ammonia stripping as well as the fertilizer effectiveness of the products obtained through these processes. However, given the breadth of the subject, we decided to treat these subjects within two separate systematic reviews rather than as secondary questions within one systematic review, see Fig. 3. Although the present systematic review and the systematic review of the fertilizer effectiveness of struvite and ammonium sulphate used separate search strings to find relevant literature, search results were combined and screened together. This was done as it was anticipated that some of the studies would include findings relevant for both reviews. At the full text screening stage included studies were marked as relevant to either this review or the fertilizer effectiveness review. After screening and coding, analysis and synthesis of findings was done separately for each review, and outcomes of critical appraisal, study findings and synthesis were presented separately. As such, the original primary question from the protocol, i.e. whether struvite

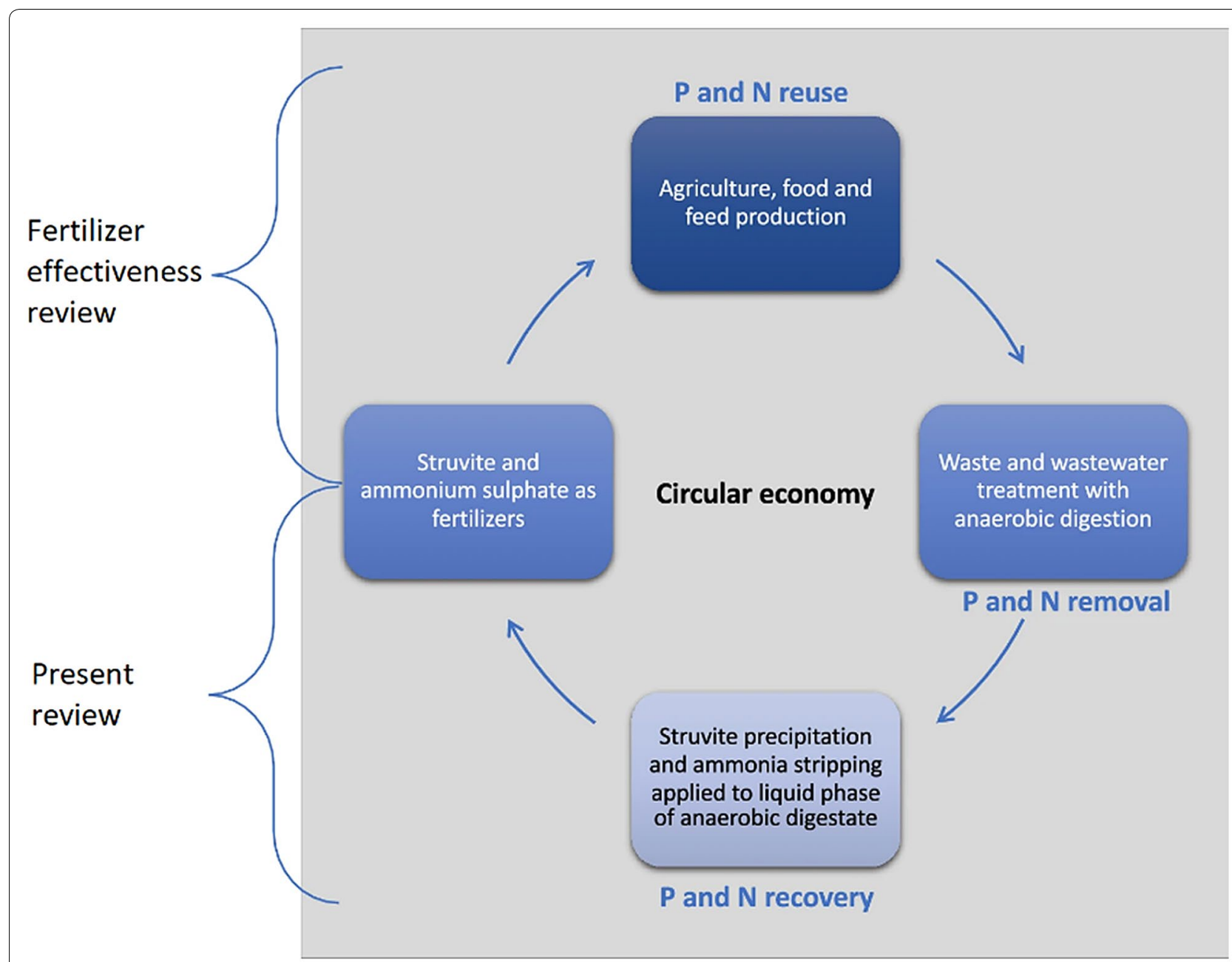

Fig. 3 Conceptual diagram with review context and questions. The diagram is simplified, and it is showing an ideal system. There are P and N losses along the cycle. Adapted from Macura et al. (2019) [27] 
precipitation and ammonia stripping are effective technologies regarding both recovery and reuse of $\mathrm{N}$ and $\mathrm{P}$ from anaerobic digestate, will not be answered explicitly in either of the reviews. Instead, the original primary question will be answered by looking at the findings of both reviews together.

\section{Searching for articles}

Bibliographic databases We searched for evidence in the following databases:

1. Scopus

2. Web of Science (WoS) Core Collections (consisting of the following indexes: SCI-EXPANDED, SSCI, A\&HCI, CPCI-S, CPCI-SSH, and ESCI)

3. Electronic Theses Online Service (eThOS)

4. Digital Access to Research Theses (DART)

5. Directory of Open Access Journals (DOAJ)

Searches were performed in March 2019 using subscriptions of Warsaw University of Life Sciences and Stockholm University. These searches were conducted using English language search terms. All searches were restricted to articles published after 2013. This was partly done to be able to build on the mapping work previously done within the same project $[17,18]$, partly to limit the amount of work to a manageable level, but also to only include studies that reflect the current level of knowledge. The following search strings were used in bibliographic databases:

(struvite OR "MgNH4PO4" OR "NH4MgPO4" OR "Magnesium ammonium phosphate" (ammonium AND (sulphate* OR sulfate* OR nitrate*)) OR mascagnite* OR ((stripp* OR scrub*) AND (ammoni* OR NH3 OR nitrogen OR air OR steam))) AND (digest* OR centrate* OR supernatant* OR dewater* OR "solidliquid" OR "bio refiner*" OR "reject water" OR effluent* OR "liquid phase") [shown as formatted for WoS].

All the search details including search dates, settings and results of WoS, Scopus, eThOS, DOAJ, DART are available in Additional file 2.

Search engines Searches in Google Scholar were performed between March and December of 2019. Searches were performed in English, Swedish, Finnish and Polish. Google Scholar searches were restricted to articles published after 2013, as above. The first 1000 search results were extracted as citations using Publish or Perish software [28] and introduced into the duplication removal and screening workflow alongside records from bibliographic databases. See Additional file 2 for details about Google Scholar searches including the search strings used, date of the searches and search results.
Organisational websites Additionally, to identify grey literature, searches were performed across a suite of relevant organisational websites. Each website was manually searched for relevant publications, using synonyms of terms related both to struvite precipitation and ammonia stripping, as well as to combinations of outcome and recovery/reuse terms. Searches were performed in English, Swedish, Finnish and Polish, corresponding to the case-study countries within the BONUS RETURN project. The results from the organisational website search along with the used search terms for each website can be found in Additional file 2.

Additional sources The present systematic review was conducted in parallel with another systematic review on the fertilizer effectiveness of struvite and ammonium sulphate. The two systematic reviews used identical literature sources but different search strings. Because some of the studies included findings relevant for both systematic reviews, search results were combined and screened together.

For the fertilizer effectiveness review, the following search string was used in bibliographic databases:

(struvite OR "MgNH4PO4" OR "NH4MgPO4" OR "Magnesium ammonium phosphate" OR "Crystal green" OR mascagnite OR (ammoni ${ }^{*}$ AND (sulphate" OR sulfate *"))) AND (fertili* OR field" OR farm* OR soil* OR agricult* OR arable OR agron* OR nutrient* OR crop* OR seed" OR food* OR yield* OR produc* OR uptake OR plant* OR vegetat* OR absor*) [shown as formatted for WoS].

Records from both reviews were screened together for efficiency. During the screening process articles were marked as relevant to either (or both) of the reviews.

Additionally, the bibliographies of all relevant review articles found were searched for relevant articles. Bibliographies of all relevant review articles were screened separately.

Testing comprehensiveness of the search To examine whether the search strategy can locate relevant evidence, the search results were compared with a list of 'benchmark' articles known to the research team to be of relevance to the review. Some benchmark articles were not found by the initial search string, and search terms were examined to identify the reasons why articles were missed and modified accordingly. The final search strings captured all the benchmark articles.

Assembling library of search results Results of the searches in bibliographic databases and Google Scholar were combined, and duplicates removed prior to 
screening. A library of search results was assembled in the review management software 'EPPI reviewer' [29]. Literature from organisational websites was screened separately before being combined with other records.

\section{Article screening and study eligibility criteria}

Screening process Screening was conducted at two levels: title and abstract level (conducted together for efficiency), and full text level. The full texts were retrieved, tracking those that could not be located or accessed. Retrieved records were screened at full text. A list of unobtainable records is available in Additional file 3. Prior to commencing screening, consistency checking was performed on a subset of articles (10\%) at both title and abstract level and full text level screening to assure screening consistency of all reviewers on the team. A subset of title and abstract records and full texts was independently screened by up to three reviewers. The results of the consistency checking were compared between reviewers and all disagreements were discussed in detail. Where the level of agreement was low (below 80\% agreement), further consistency checking was performed on an additional set of articles and then discussed. Following consistency checking (i.e. when agreement was above $80 \%$, lowest level of agreement reached $80.4 \%$ ), records were screened by one experienced reviewer. EPPI reviewer's machine learning component was not used for screening as this component was not publicly launched at the time when screening was done.

Study eligibility criteria The following criteria was applied at all levels of screening:

- Eligible population(s) Liquid phase of anaerobic digestate from agricultural residuals and domestic wastewater (including blackwater). Studies were included without geographical limitations.

- Eligible intervention(s) Struvite precipitation and ammonia stripping undertaken for the purposes of recovering $\mathrm{N}$ and $\mathrm{P}$.

- Eligible comparator(s) Inflow concentrations served as a control.

- Eligible outcome(s) Recovery potential of N compounds (total N, ammonium and/or ammonia) and $\mathrm{P}$ compounds (total $\mathrm{P}$, phosphate) expressed as recovered percentage in the digestate flow stream and/or total recovery in the wastewater.

- Eligible languages: English, Finnish, Polish and Swedish.

Additional file 4 includes a list of articles excluded at title and abstract level and at full text level, with reasons for exclusion.

\section{Study validity assessment}

Eligible studies were subject to a study validity assessment. The assessment evaluated external and internal study validity and categorised relevant studies accordingly. The detailed criteria for the study validity assessment of eligible studies (i.e. critical appraisal tool) was developed and trialed during the review process in several meetings with subject experts. The critical appraisal tool was tested on a set of $10 \%$ of studies by the entire team. There were no reviewers on our team who have authored articles considered within the review.

Study validity assessment included evaluation of (1) study set up and design flaws (due to calculation errors, invalid outcome measurements or failure to control for the effect of additional competing interventions such as irradiation, dialysis or microwave treatment) and (2) susceptibility to bias (in the form of reporting bias, i.e. selective reporting of study findings). Studies judged to have flaws in design and setup or reporting bias were excluded from the narrative and quantitative synthesis. Then, studies without these issues were assessed for clarity of reporting on reactor input, recovery process and composition of the final product. Studies deemed to be unclear on two or more of these domains were classified as 'unclear' and excluded from quantitative synthesis but were still included in the narrative synthesis. The studies that passed both of these two appraisal steps were included in the quantitative synthesis. Since all the studies included in the quantitative synthesis were judged to be similar in quality, no distinction was made between different quality studies, and as such no weighting was done. The validity of each study was assessed by two independent reviewers. Final decisions regarding doubtful cases were taken by the whole review team. Additional file 5 includes details of critical appraisal criteria and a full list of all eligible studies, including the ones excluded based on validity assessment along with the reasons for exclusion.

\section{Data coding and extraction strategy}

Data were extracted from eligible studies and recorded in spreadsheets that included pre-determined coding. Information was extracted on study characteristics, intervention details, comparators, effect modifiers and study findings. Raw data, i.e. $\mathrm{pH}, \mathrm{Mg}$ source, removal efficiency and molar ratios of $\mathrm{P}, \mathrm{N}$ and $\mathrm{Mg}$ was extracted from the struvite precipitation studies that were included in the quantitative synthesis. Study findings (including the outcome values) were extracted from tables and graphs using the image analysis software WebPlotDigitizer (https://automeris.io/WebPlotDigitizer/) where needed. Missing parameters (such as unpublished efficiencies or concentrations) were calculated from reported raw data 
whenever possible. The review team did not ask authors of relevant articles for access to unpublished raw data. All extracted data records are in Additional file 6.

Prior to coding and data extraction, a coding and data extraction consistency checking exercise was done independently by each reviewer on a subset $(10 \%)$ of records by all reviewers. All disagreements were discussed, and the coding scheme was clarified where needed.

\section{Potential effect modifiers/reasons for heterogeneity}

The following factors, which potentially can cause variation in measured outcomes, were considered and recorded if reported in primary studies. The list was refined during the review process based on consultations with experts on the review team.

- Specific characteristics of intervention and process parameters including temperature, $\mathrm{pH}$, inflow concentrations, molar ratios of reactants, amount of chemicals added and hydraulic retention time

- Type of substrate used for anaerobic digestion

- Type of treatment processes before anaerobic digestion phase and before application of struvite precipitation or ammonia stripping

- Study design including study scale, reactor setup \& type

\section{Data synthesis and presentation}

We have synthesized findings in a narrative and quantitative form. A narrative synthesis described the validity of the results along with a summary of findings (in a graphical and tabular form) for each study passing the criteria specified in the section 'Study validity assessment' (see Additional file 7). In addition to the narrative synthesis, quantitative synthesis was performed for struvite precipitation. Due to high heterogeneity between studies and lack of data, no quantitative synthesis was performed for ammonia stripping. In the struvite precipitation dataset, the effect of selected process parameters on the removal efficiency of $\mathrm{PO}_{4}$ was investigated. Removal, rather than recovery, was chosen as the measure of outcome since this is what most studies report (removal and recovery rates are relatively similar for struvite precipitation). The investigated parameters were $\mathrm{pH}, \mathrm{Mg}$ source (such as $\mathrm{MgO}$ or $\mathrm{MgCl}_{2}$ ) and ratio of $\mathrm{Mg}: \mathrm{PO}_{4}$.

\section{Quantitative synthesis for struvite precipitation dataset}

The main objective of the data synthesis was to derive quantitative models of the $\mathrm{PO}_{4}$ removal and understand how the removal is influenced by $\mathrm{pH}, \mathrm{Mg}: \mathrm{PO}_{4}$ ratio and $\mathrm{Mg}$ source. The statistical analyses involved the following steps:
1. Handling of extreme values

2. Calculation of mean values

3. Fitting and selection of prediction models

4. Graphical presentations of models and prediction errors

Scatter charts of the two-dimensional distribution of $\mathrm{pH}$ and $\mathrm{Mg}: \mathrm{PO}_{4}$ revealed that, with few exceptions, the majority of $\mathrm{PO}_{4}-\mathrm{P}$ removal was measured within the following parameters: $7 \leq \mathrm{pH} \leq 11$ and $0 \leq \mathrm{Mg}: \mathrm{PO}_{4} \leq 4$ (see Fig. 4).

Data outside this value space were considered too sparse for modelling the $\mathrm{PO}_{4}-\mathrm{P}$ removal and thus excluded in the subsequent statistical analyses (for the list of excluded data points, see Additional file 6, sheet 2. Outliers). In addition, we excluded data from a study during data extraction stage since we found (through recalculation using the raw data provided by the authors) that the reported values of ratio of $\mathrm{Mg}: \mathrm{PO}_{4}$ were wrong. Apart from these two exceptions all extracted data were used (for details see Additional file 6, sheet 2. Outliers). The studies from which data were extracted varied with respect to the experimental design that was used. Specifically, there were few studies with replicated experiments, and few studies in which both the $\mathrm{pH}$ and $\mathrm{Mg}: \mathrm{PO}_{4}$ ratio were varied at the same time. Together, this meant it was not feasible to assign meaningful standard errors to the observed mean $\mathrm{PO}_{4}-\mathrm{P}$ removal in individual studies. To overcome the abovementioned difficulties, we compiled a dataset containing the average $\mathrm{PO}_{4}$ removal for each of the 199 investigated combinations of substrate, $\mathrm{pH}, \mathrm{Mg}: \mathrm{PO}_{4}$ ratio and $\mathrm{Mg}$ source. Thereafter, regression models were fitted to the entire dataset and to subgroups representing specific types of substrates. This approach had the advantage that the models were primarily fitted to studies with a good experimental design in which both $\mathrm{pH}$ and ratio of $\mathrm{Mg}: \mathrm{PO}_{4}$ ratio were varied, whereas studies in which these two variables were fixed played a minor role. An ideal regression model would be able to produce both accurate estimates of the expected removal for a great variety of substrates, $\mathrm{Mg}$ sources, levels of $\mathrm{pH}$ and $\mathrm{Mg}: \mathrm{PO}_{4}$ ratios as well as reliable uncertainty estimates. Considering that the available dataset was too small to enable both a flexible structure of the mean function and an advanced correlation structure, any regression model is a compromise. We decided to prioritize smoothing techniques allowing flexible models of the expected removal and accept that uncertainty estimates and p-values of statistical significance may be underestimated because all observations in such models are regarded as statistically independent. More specifically, we decided to fit generalized additive models (GAM) to data. GAM is a class of smoothing techniques in which a univariate 


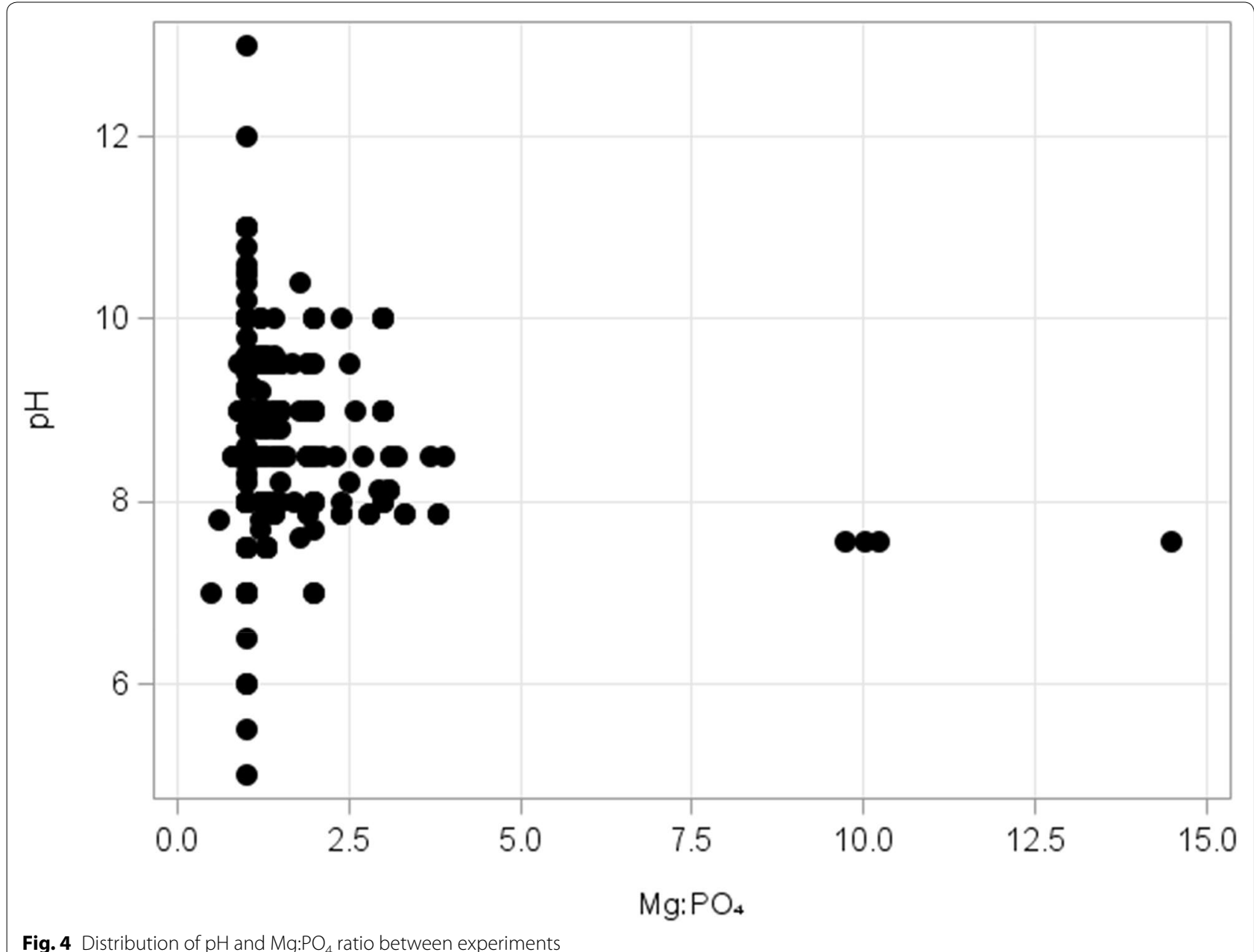

response variable is related to smooth functions of a set of predictors [30]. In its original form, the expected value $E(Y)$ of the response variable (or a function $g(E(Y)$ ) of this value) was assumed to be a sum of smooth functions of a set of predictors $\mathrm{x}_{1}, \mathrm{x}_{2}, \ldots, \mathrm{x}_{\mathrm{p}}$ and as follows:

$$
E(Y)=s_{1}\left(x_{1}\right)+s_{2}\left(x_{2}\right)+\ldots+s_{p}\left(x_{p}\right) \quad(\text { model } 1)
$$

where $s_{1}, s_{2}, \ldots, s_{p}$ are estimated from the given data. If data are divided into classes, model 1 can be extended with constants representing systematic level shifts between the different classes. Current GAM procedure also makes it possible to fit models of the type:

$$
E(Y)=\operatorname{spline} 2\left(x_{1}, x_{2}\right) \quad(\text { model } 2)
$$

here spline2 is smooth response surface, a so-called thin plate spline, in two variables. The main difference between models 1 and 2 is that model 1 assumes that the response to $x_{1}$ is the same for all levels of $x_{2}$, whereas model 2 allows interaction effects of $x_{1}$ and $x_{2}$. In our review, the removal of $\mathrm{PO}_{4}$ expressed in percent was selected as response variable $\mathrm{Y}$, whereas $\mathrm{pH}$ or $\mathrm{Mg}: \mathrm{PO}_{4}$ ratio, or both, were used as predictors. In some analyses of the entire dataset, Eq. 1 was extended with constants representing different types of substrates. For the full results of the model fitting, see Additional file 8. All analyses involving GAM models were performed using a procedure called proc GAM in SAS Enterprise Guide 6.1.

\section{Meta-analyses of the struvite precipitation dataset}

The struvite precipitation experiments included in the quantitative synthesis were subjected to meta-analyses, which were performed using proc MIXED in the statistical software package SAS Enterprise Guide 6.1. More specifically, to separate variation between and within studies, the extracted data were fitted to variance component models 


$$
Y=\beta+b+\varepsilon
$$

in which $\mathrm{Y}$ is a vector of observed effect sizes (struvite recovery data in percent), the intercept $\beta$ denotes the expected effect size, $b$ is a vector of random errors (residuals) on the between-study level, and $\varepsilon$ is a vector of random errors (residuals) on the within-study level. Separate analyses were performed on the entire dataset and subsets representing struvite precipitation from manure and sewage sludge, respectively. In all cases, the confidence limits for the expected effect size were based on the assumption that the random errors on the between-study and within-study levels were independent and normally distributed.

\section{Review findings}

All searches (combined from this and a parallel review on fertilizer effectiveness) yielded 6573 records. Google scholar searches in English, Swedish, Polish and Finnish yielded no relevant records (please see Additional file 2 for details). After removing duplicates (2764), 3809 records were screened on title and abstract. Out of 945 included records, $81 \%$ were retrieved. After full text screening of 762 records, we included 62 articles for the critical appraisal stage (from the initially screened 87 full texts we excluded 27 that were relevant for the fertilizer effectiveness review, and included 1 article from the bibliographies of relevant reviews as well as 1 from grey literature sources). Articles were divided into 'studies' and 'experiments'. Studies were defined as following a specific treatment train, i.e. treatments being conducted by the same lead group of authors utilizing one specific reactor setup. In each article there can be several studies, and studies can be reported across different articles. Experiments were defined as individual reactor runs. Studies can contain several experiments, i.e. if process parameters (such as $\mathrm{pH}$ and temperature) are varied within the same treatment train. In the critical appraisal stage, 25 studies were removed. In summary, the evidence base included 30 studies on struvite precipitation and 8 studies on ammonia stripping that were synthesised narratively. Out of the 30 studies included in the struvite precipitation evidence base, 28 were included in the quantitative synthesis and 2 were excluded due to missing data. Within the included studies, some outlier experiments were excluded as explained in the section "Data synthesis and presentation" and detailed in Additional file 6. Due to high heterogeneity among studies, quantitative synthesis could not be performed for ammonia stripping studies (see Narrative synthesis for ammonia stripping studies section). All the literature sources used in the review and the number of studies included and excluded at different stages of the review process are presented in Fig. 5.

\section{Characteristics of studies included in narrative synthesis}

All included studies (38) originated from 37 articles (one article included 2 studies). All the included publications were journal articles and were published mostly in 2018 (note that the low number of articles in 2019 reflects search dates and indexing delays of different literature sources that were used) (see Table 1).

\section{Overview of struvite precipitation evidence base}

The evidence base for struvite precipitation included 30 studies and 298 experiments. Out of all included studies that reported location, over half were conducted in Asia. Specifically, most were conducted in China, see Table 2 .

The substrates included were sewage sludge (16 studies/53\%) as well as different types of manure (14 studies/47\%) (Fig. 6).

Most of the studies were conducted on small scale (27 studies/90\%). These were laboratory or bench scale operations with reactor volumes from a couple of millilitres to up to $10 \mathrm{~L}$. Only $3(10 \%)$ of the studies were classified as medium scale (defined as pilot scale operations with reactor volumes from 100 to up to $5000 \mathrm{~L}$ ). There were no large-scale experiments (i.e. full-scale wastewater treatment plant operations). The majority of experiments were conducted using batch reactor setups (277 experiments/93\%), while the rest (21 experiments/7\%) were conducted using continuous flow reactor setups.

Sources of $\mathrm{Mg}$ included $\mathrm{MgCl}_{2}$ (183 experiments/61\%), $\mathrm{MgO} \quad\left(50\right.$ experiments/17\%), $\quad \mathrm{MgSO}_{4} \quad(29$ experiments/10\%), $\mathrm{Mg}(\mathrm{OH})_{2}$ (25 experiments/8\%) and Seawater (including bittern, which is a by-product from salt production from seawater) (10 experiments/3\%) (Fig. 7). In one of the experiments, only the existing $\mathrm{Mg}$ in the waste stream was used for the reaction (Table 3).

\section{Narrative synthesis for struvite precipitation evidence base}

Twenty-five studies were excluded during critical appraisal due to: presence of competing or additional interventions that were not controlled for (14), design flaws (3), reporting bias (2) and clarity issues (5). Further, 1 study was removed since $\mathrm{NH}_{4}$, rather than $\mathrm{PO}_{4}$, was limiting the reaction in all experiments. During quantitative synthesis, 2 studies were excluded since they lacked data on process parameters, and 5 experiments were removed as outliers (see Additional file 6, sheet 2. Outliers). All the included studies reported $\mathrm{pH}$, which varied 
ROSES Flow Diagram for Systematic Reviews. Version 1.0
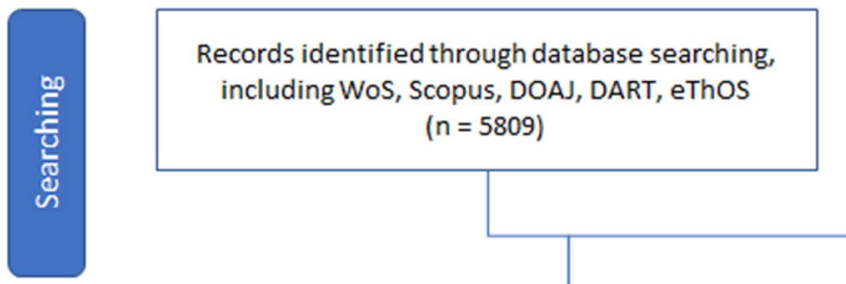

Records identified through Google Scholar searches in English language

$$
(n=764)
$$
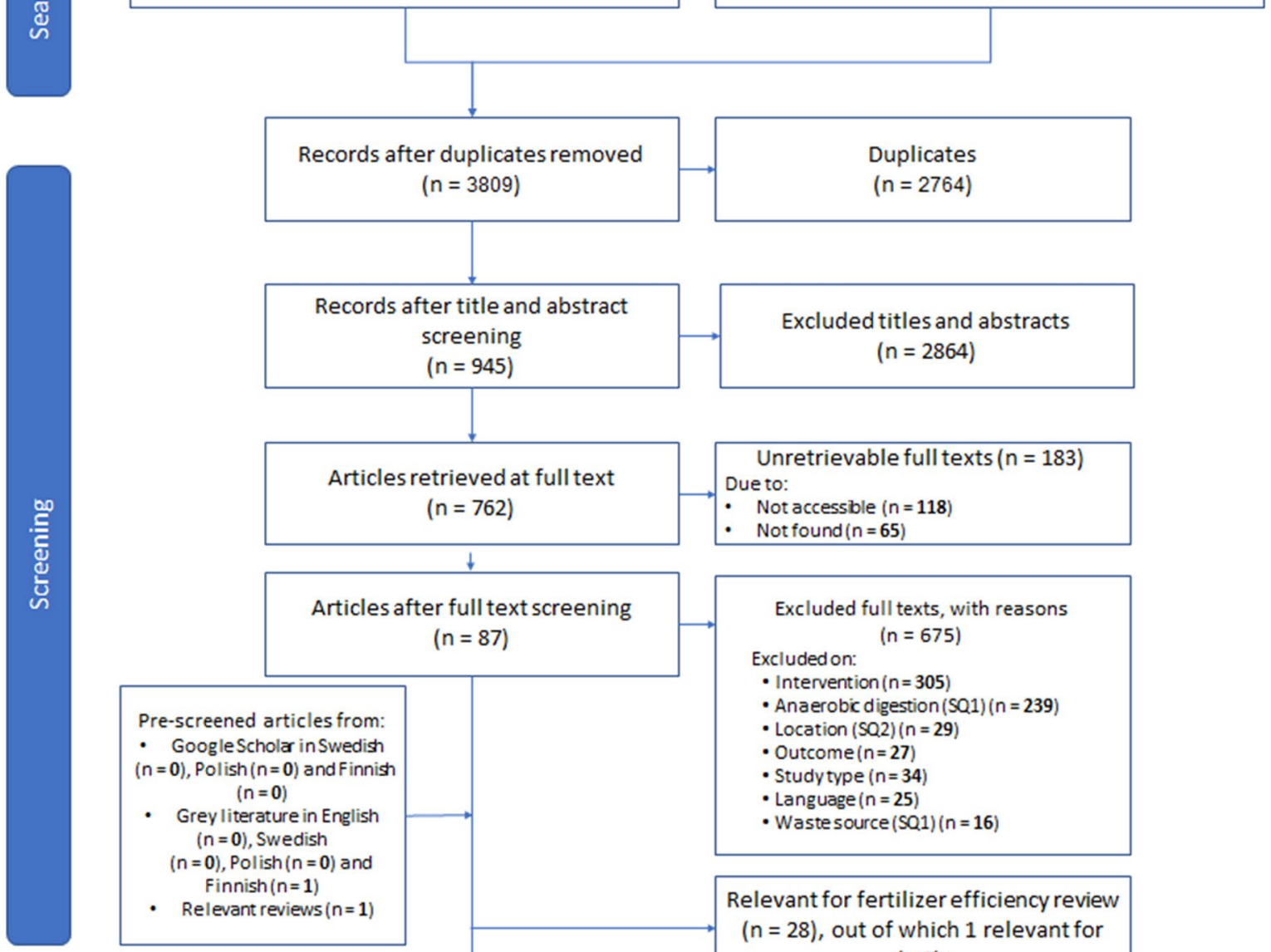

Records after title and abstract screening $(n=945)$

Excluded titles and abstracts

$(n=2864)$

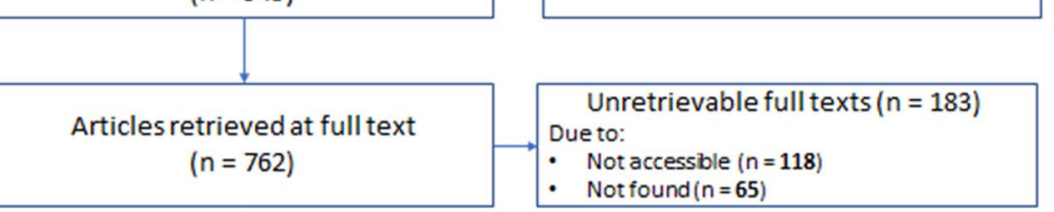

Articles after full text screening $(n=87)$

\section{Pre-screened articles from: \\ - GoogleSchola in Swedist \\ $(n=0)$, Polish $(n=0)$ and Finnish $(n=0)$ \\ - Grey literature in English $(n=0)$, Swedish \\ $(n=0)$, Polish $(n=0)$ and Finnish $(n=1)$ \\ - Relevant reviews $(n=1)$}
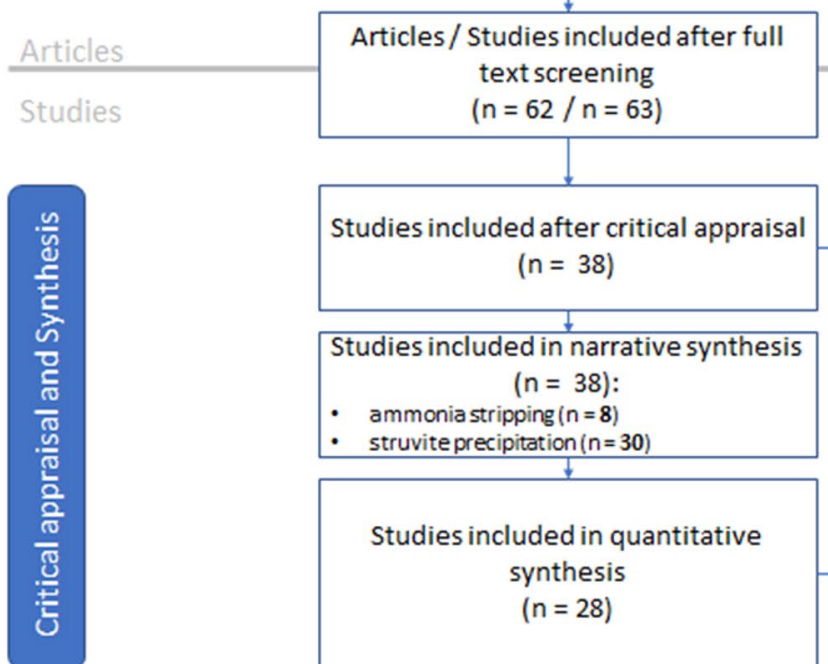

\section{Studies included after critical appraisa $(n=38)$}

Studies included in narrative synthesis

$$
(n=38) \text { : }
$$

- ammoniastripping $(n=8)$

- struvite precipitation $(n=30)$

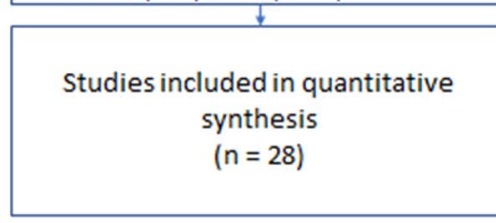

Excluded full texts, with reasons

$$
\text { ( } n=675 \text { ) }
$$

Excluded on:

- Intervention ( $n=305)$

- Anaerobic digestion (SQ1) ( $n=239$ )

- Location (SQ2) ( $n=29)$

- Outcome ( $n=27)$

- Study type $(n=34)$

- Language $(n=25)$

- Waste source $(\mathrm{SQ1})(\mathrm{n}=16)$

Relevant for fertilizer efficiency review $(n=28)$, out of which 1 relevant for both

Fig. 5 ROSES flow diagram [31] showing all literature sources and inclusion/exclusion process for relevant studies 
Table 1 Publication year of included articles

\begin{tabular}{lc}
\hline Publication year & $\begin{array}{l}\text { Number } \\
\text { of articles }\end{array}$ \\
\hline 2013 & 7 \\
2014 & 4 \\
2015 & 5 \\
2016 & 5 \\
2017 & 4 \\
2018 & 11 \\
2019 & 1 \\
\hline
\end{tabular}

Table 2 Location of included studies

\begin{tabular}{lll}
\hline Continent & Country & $\begin{array}{l}\text { Number } \\
\text { of studies }\end{array}$ \\
\hline Asia & China & 13 \\
& Israel & 1 \\
South Korea & 2 \\
Australasia & Australia & 1 \\
Europe & Denmark & 1 \\
Europe & France & 1 \\
& Spain & 3 \\
North America & Sweden & 1 \\
South America & Canada & 2 \\
No location stated & USA & 2 \\
\hline
\end{tabular}

between 5 and 13, as well as $\mathrm{Mg}: \mathrm{PO}_{4}$ ratio, which varied between $0.5: 1$ and 14.5:1. The experimental design varied strongly between studies. Among a total of 26 studies that were examined only 12 were subjected to an experimental design with true replicates, i.e. 2 or more experiments for at least some of the examined combinations of substrate, $\mathrm{pH}$, ratio of $\mathrm{Mg}: \mathrm{PO}_{4}$ and $\mathrm{Mg}$ source. Furthermore, the studies varied strongly with respect to the distribution of design points. Among a total of 35 combinations of substrate and $\mathrm{Mg}$ source that were examined only 11 had a design in which both $\mathrm{pH}$ and ratio of $\mathrm{Mg}: \mathrm{PO}_{4}$ were varied. For 12 of the 35 combinations both $\mathrm{pH}$ and $\mathrm{Mg}: \mathrm{PO}_{4}$ were held fixed, and for the remaining 12 combinations either $\mathrm{pH}$ or ratio of $\mathrm{Mg}: \mathrm{PO}_{4}$ was fixed. Removal efficiency varied between 0.1 to $100 \%$ with respect to $\mathrm{PO}_{4}$. Certain process parameters appear to have a clear influence on the outcome, specifically $\mathrm{pH}$ and the $\mathrm{Mg}: \mathrm{PO}_{4}$ ratio (see section Data synthesis for struvite precipitation evidence base). For a complete list of the studies included in the evidence base and narrative synthesis along with the summary of individual study findings, see Additional file 7.
Results of meta-analyses of the struvite precipitation dataset The descriptive analyses of the struvite precipitation dataset showed that the recovery of struvite was substantial regardless of the type of substrate and other conditions in the performed experiments. This was confirmed by the meta-analysis, in which a variance component model was fitted to the dataset already subjected to descriptive analyses (See Table 1 in Additional File 9). Separate meta-analyses of struvite precipitation from manure and sewage sludge, respectively, provided further evidence that struvite can be recovered regardless of the substrate (See Tables 2 and 3 in Additional File 9).

Together the meta-analyses also showed that the variation within studies was larger than the variation between studies. This was expected considering that a majority of the reviewed studies aimed to examine under what conditions struvite precipitation is effective. For the same reason, this review focused on surface response modelling of struvite precipitation.

\section{Data synthesis for struvite precipitation evidence base}

The studies included in the final evidence base were judged to all be of the same validity and the influence of methodological differences among studies to the outcome was not tested in the quantitative synthesis. In general, high removal rates were achieved, with mean and median removal rates of $\mathrm{PO}_{4}$ reaching $86.2 \%$ and $91.8 \%$, respectively (see Additional file 6).

Both $\mathrm{pH}$ and the ratio of $\mathrm{Mg}$ to $\mathrm{PO}_{4}$ were found to have a clear influence on the removal rates. When analysing removal rates under different $\mathrm{pH}$ values (regardless of substrate type or $\mathrm{Mg}: \mathrm{PO}_{4}$ ratio), the response to $\mathrm{pH}$ was found to be non-linear, with a maximum average removal found to be around $\mathrm{pH} 9.5$ (Fig. 8). The response to $\mathrm{pH}$ for removal rates on sewage sludge took on the shape of a bell curve with maximum removal around $\mathrm{pH} 9.5$ (Fig. 9, left). When examining removal rates of manure experiments only, the trend of the response was not quite as pronounced (Fig. 9, right).

When examining experiments on all types of included substrates, the response in removal efficiency to $\mathrm{Mg}: \mathrm{PO}_{4}$ ratio was found to be almost linear, with an average of around $85 \%$ removal at 1:1 ratio, increasing to approach almost complete removal at 4:1 ratio (Fig. 10). Similar trends were observed when examining experiments on sewage sludge and manure individually (Fig. 11). It should be noted that although average removal was found to increase with higher $\mathrm{Mg}: \mathrm{PO}_{4}$ ratio, almost complete removal was reported for some experiments with ratios as low as 1 to 1 (see Additional file 6).

When examining the influence of $\mathrm{Mg}$ source on the removal of $\mathrm{PO}_{4}-\mathrm{P}$, no obvious differences between different Mg sources were observed (Fig. 12). As a result, Mg source was not included as a variable in the prediction models. 


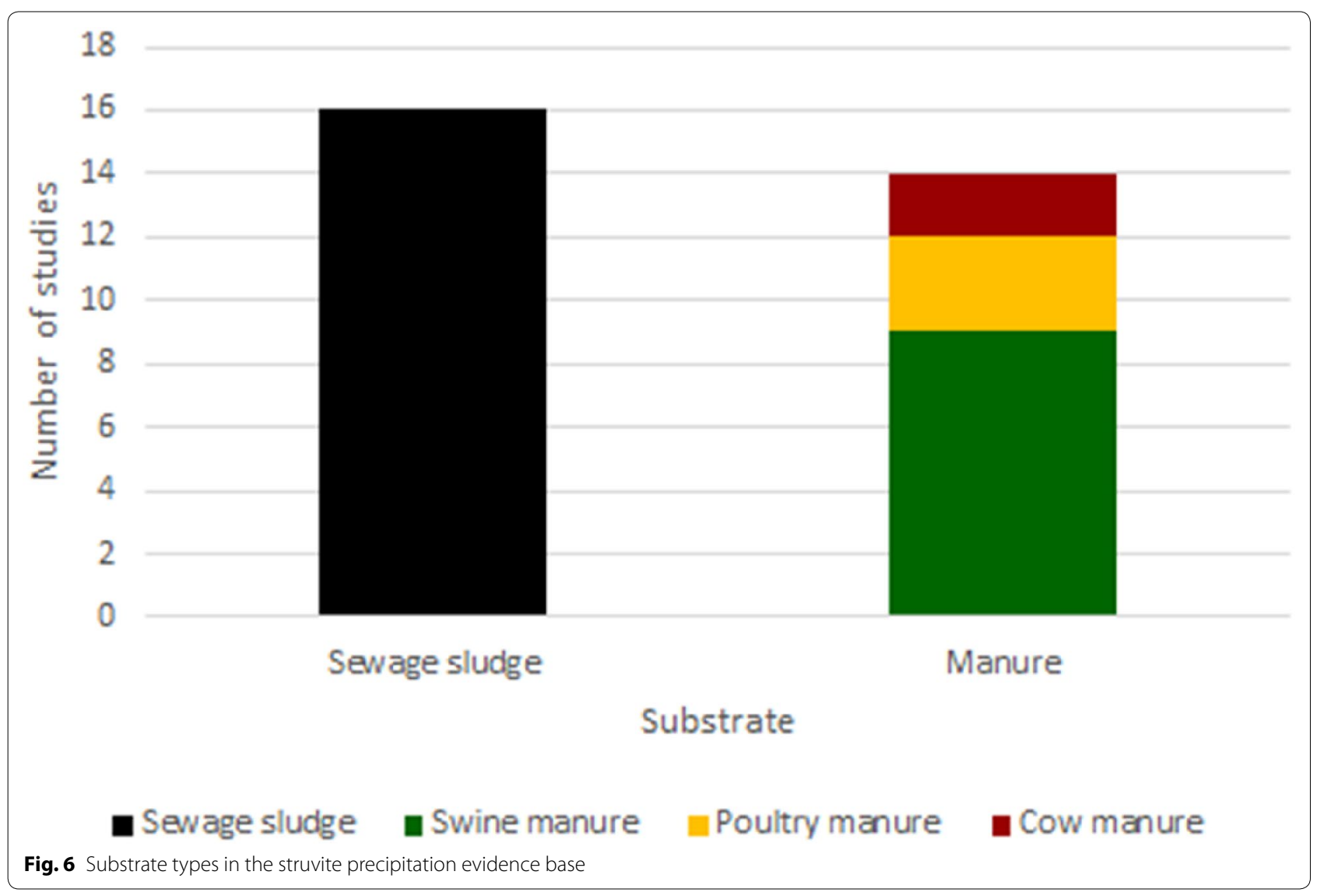

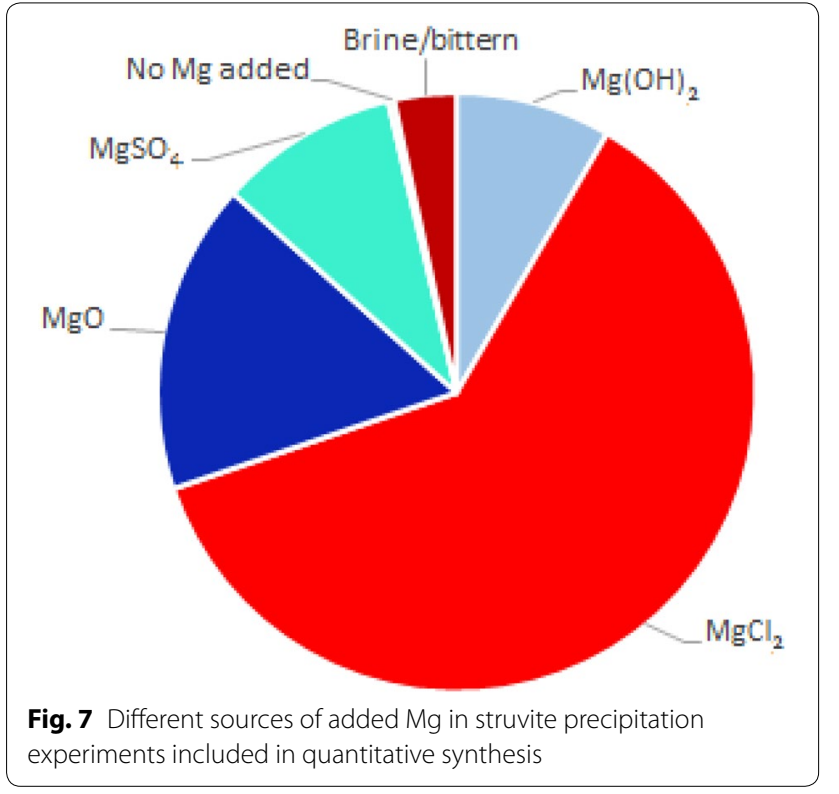

The results for the additive and the thin plate models of $\mathrm{PO}_{4}-\mathrm{P}$ removal as a function of $\mathrm{pH}$ and $\mathrm{Mg}$ to $\mathrm{PO}_{4}$ ratio were relatively similar. Both models show that maximum removal is achieved around $\mathrm{pH} 9.5$, and that removal increases with $\mathrm{Mg}: \mathrm{PO}_{4}$ ratio (Fig. 13). Note that in an additive GAM model the response to changes in one variable is the same for all levels of the other variable. The additive GAM model in which substrate was used as an explanatory variable for $\mathrm{PO}_{4}-\mathrm{P}$ removal showed similar results as well (see Additional file 8, see Fig. set 9). In general, all models suffered from substantial random variation that could not be further explored given the rather small sample sizes. However, this did not jeopardise the general conclusion that $\mathrm{pH}$ and $\mathrm{Mg}: \mathrm{PO}_{4}$ ratio have clear impacts on the removal efficiency of $\mathrm{PO}_{4}$-P. A more detailed version of the quantitative synthesis, including sub-group analyses with different substrates as well as a summary of different models fits, is available in Additional file 8 . 
Table 3 The records included in the struvite evidence base

\begin{tabular}{lll}
\hline References & Substrate & Study scale \\
\hline Bohdziewicz et al. (2012) [32] & Sewage sludge & Laboratory \\
Connan et al. (2018) [33] & Sewage sludge & Laboratory \\
Garcia-Belinchón (2013) [34] & Sewage sludge & Laboratory \\
Huang et al. (2015) [35] & Sewage sludge & Laboratory \\
Jia et al. (2017) [36] & Sewage sludge & Laboratory \\
Kalam (2015) [37] & Sewage sludge & Laboratory \\
Karabegovic et al. (2013) [38] & Sewage sludge & Laboratory \\
Lahav et al. (2013) [39] & Sewage sludge & Laboratory \\
Muhmood et al. (2018) [40] & Sewage sludge & Medium \\
Qin et al. (2018) [41] & Sewage sludge & Laboratory \\
Sharp et al. (2013) [42] & Sewage sludge & Medium \\
Xavier et al. (2014) [43] & Sewage sludge & Laboratory \\
Zheng et al. (2014) [44] & Sewage sludge & Laboratory \\
Lee et al. (2015) [45] & Swine manure & Laboratory \\
Castro et al. (2018) [46] & Cow manure & Medium \\
Farrow et al. (2017) [47] & Poultry manure & Laboratory \\
Huang et al. (2014) [48] & Swine manure & Laboratory \\
Jiang et al. (2018) [49] & Swine manure & Laboratory \\
Kim et al. (2016) [50] & Swine manure & Laboratory \\
Lin et al. (2018) [51] & Swine manure & Laboratory \\
Muhmood et al. (2018) [52] & Poultry manure & Laboratory \\
Shen et al. (2016) [53] & Swine manure & Laboratory \\
Wang et al. (2018) [54] & Swine manure & Laboratory \\
Zhang et al. (2014) [55] & Poultry manure & Laboratory \\
Zhang et al. (2019) [56] & Cow manure & Laboratory \\
Balaguer-Barbosa (2018) [57] & Sewage sludge & Laboratory \\
Liu et al. (2017) [58] & Sewage sludge & Laboratory \\
Cerrillo et al. (2015) [59] & Swine manure & Laboratory \\
Crutchik et al. (2017) [60] & Sewage sludge & Laboratory \\
\hline
\end{tabular}

\section{Overview of ammonia stripping evidence base}

The evidence base for effectiveness of ammonia stripping was rather small, containing 8 studies that included 42 experiments in total. Most studies were conducted in Europe (6 studies/75\%) and 2 studies (25\%) were from China, see Table 4.

Studies included a variety of substrates, including mixtures of different substrates. Four studies (9 experiments) were conducted in a laboratory context on a small scale, 1 at medium scale ( 2 experiments) and 3 (31 experiments) at large scale. Five studies were conducted as batch experiments and 3 as continuous experiments. Five studies had a counterflow reactor configuration. The remaining 3 studies did not specify reactor configuration (Table 5).

\section{Narrative synthesis for ammonia stripping effectiveness studies}

No studies were excluded during critical appraisal. Studies were relatively heterogeneous (see "Review limitations" for details. Various digested substrates were included, including sewage sludge and different types of manure. All studies reported $\mathrm{pH}$, which varied between 8 and 12.9. The reported gas to liquid flow ratios varied between 640 to 1 and 6000 to 1 . Presented liquid and air temperatures varied between 20 and $60{ }^{\circ} \mathrm{C}$, as well as between 20 and $80{ }^{\circ} \mathrm{C}$, respectively. Only setups with counterflow reactor configuration were found. Total nitrogen removal varied between 17 and 95\%. Low data availability and high heterogeneity between studies in the evidence base precluded quantitative synthesis for ammonia stripping dataset (see section "Review limitations"). As such, no conclusions are presented regarding the influence of different process parameters on the outcome of ammonia stripping. For a complete list of the studies included in the evidence base and narrative synthesis, see Additional file 7.

\section{Review limitations}

The limitations of the review process may originate from: (1) the search strategy; and (2) bias in the pool of studies found. We will address both types of limitations consecutively.

Our searches were conducted in a limited set of languages due to the focus of the BONUS RETURN project on the Baltic Sea Region and European contexts and available language skills in the review team. However, searches in other languages (such as German, Spanish, French, Russian or Chinese) would likely produce a more extensive evidence base. These additional searches could be easily conducted with more resources. Moreover, we have limited our search to last 6 years, partly to be able to build on the mapping work previously done within the same project $[17,18]$. Future work could capture research published before 2013 for a more extensive evidence base. In order to decrease a risk of publication bias, we have searched for grey literature. Nevertheless, given that methods for assessment of publication bias are based on statistical analyses of relationships between the estimated effect size and a direct or indirect measure of the uncertainty of the estimated effect size, we could not derive this information from our data and as a result, we could not statistically assess publication bias.

Studies examining the effectiveness of struvite precipitation included substantial random variation that could not be explained with the available data. The variation might for example originate from differences in additions 


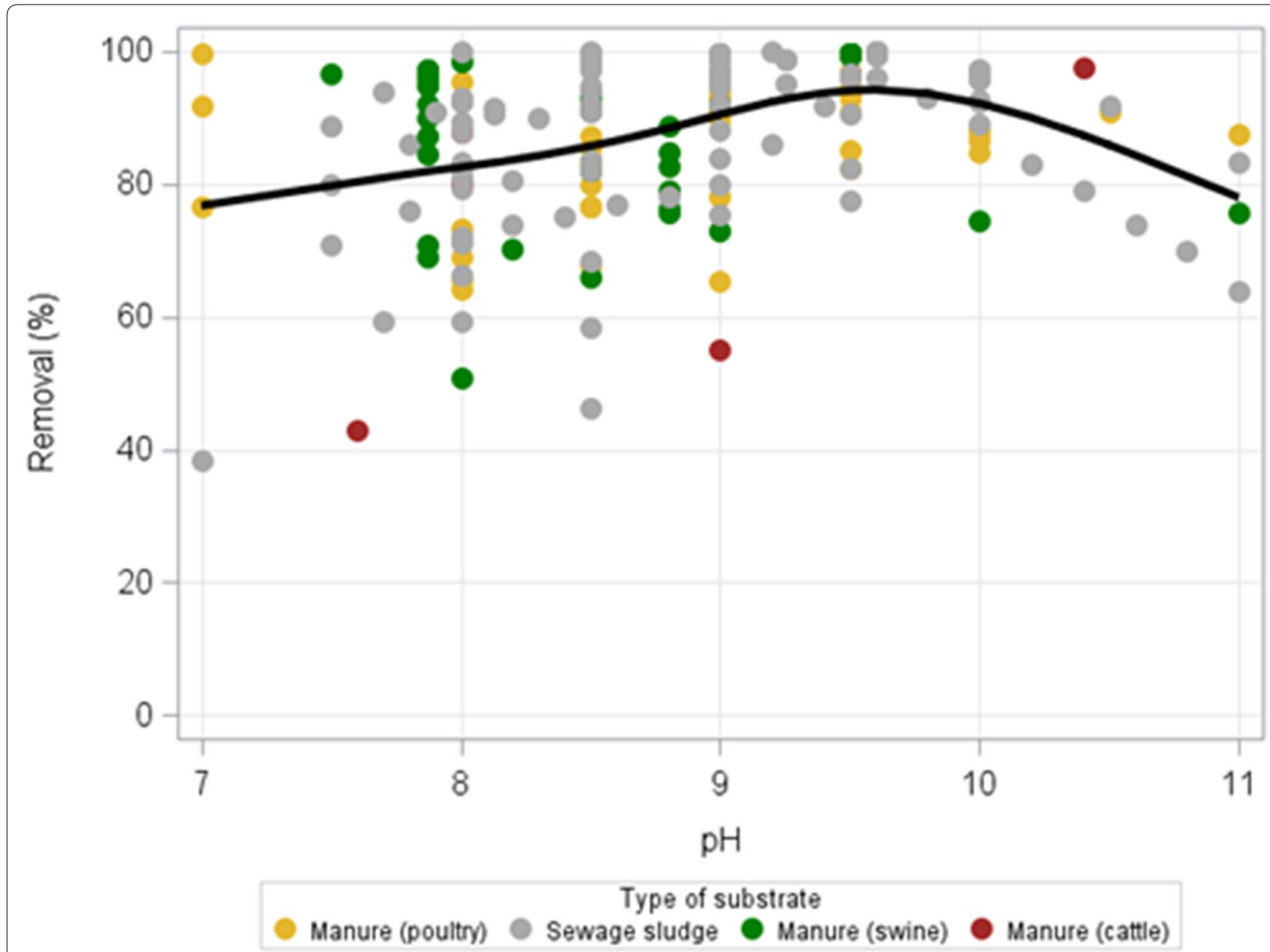

Fig. $8 \mathrm{PO}_{4}-\mathrm{P}$ removal as a function of $\mathrm{pH}$, all substrates (different substrates are shown, but the variation between different substrates was not taken into account when producing the function). Each dot represents an experiment

of seed crystals or from variations in total solids or nutrient concentrations of the inflow. However, the evidence base was neither large enough nor homogeneous enough to investigate the influence of these parameters on the outcome. The random variation, however, did not jeopardise the conclusions regarding the impact of $\mathrm{pH}$ and $\mathrm{Mg}: \mathrm{PO}_{4}$ ratio on the outcome, since these relationships were obvious. In addition, due to lack of data for some values of $\mathrm{pH}$ and $\mathrm{Mg}: \mathrm{PO}_{4}$ ratio, the predicted removal in some areas of the developed models is uncertain.

The studies on ammonia stripping displayed high heterogeneity with respect to what parameters and outcomes were reported, even though all the studies treated ammonia stripping of the liquid phase of anaerobic digestate. For example, liquid to gas flow ratio is only presented in three out of seven studies in the final evidence base. When it comes to temperature, some authors present only the air temperature, others present only the liquid temperature, and others still present only the temperature of the reactor. There are also differences in whether the authors present removal or recovery as a measure of outcome, and how they define the two. Moreover, authors apply different techniques for measuring $\mathrm{N}$ concentrations, i.e. total $\mathrm{N}$, ammonia- $\mathrm{N}$ and total ammonia nitrogen (TAN). All these issues contribute to the incomparability of the individual study findings, which complicates synthesis 

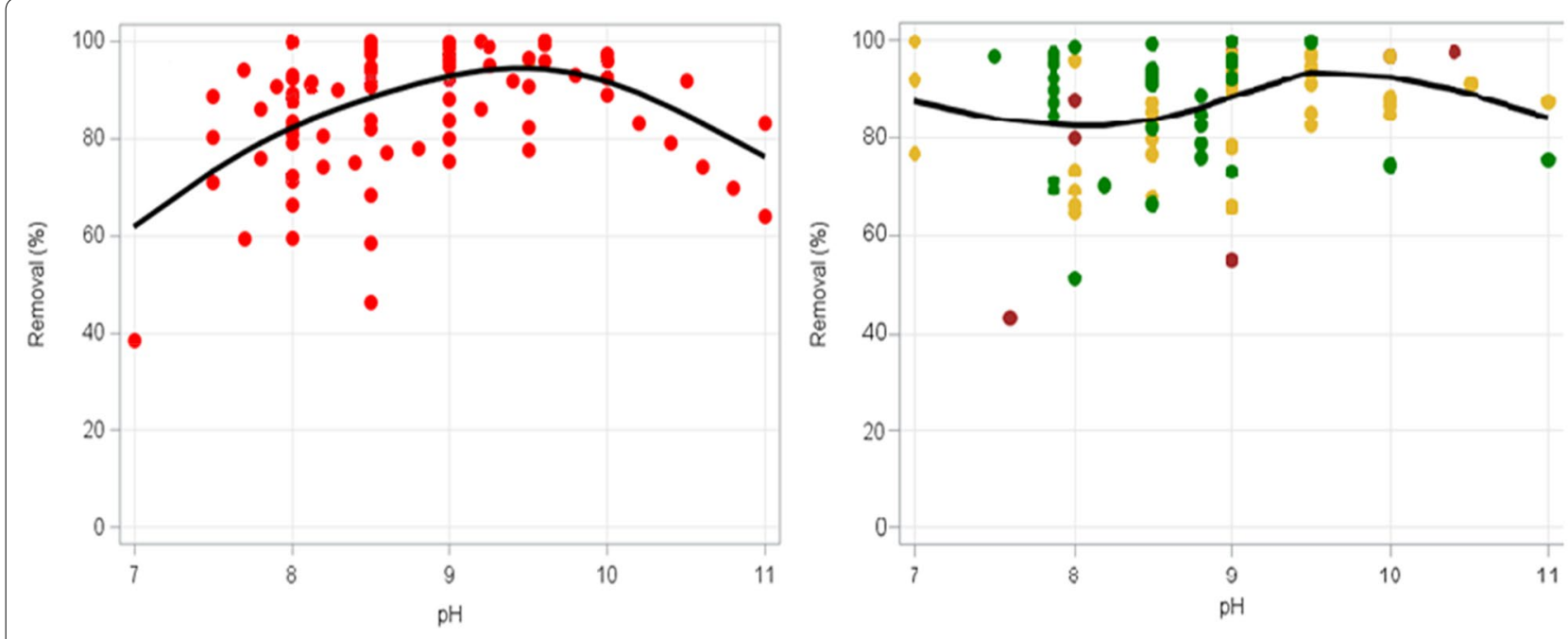

Type cf substrate - Menure poutry) - Manufe (swine) - Manute (crttle)

Fig. $9 \mathrm{PO}_{4}-\mathrm{P}$ removal as a function of $\mathrm{pH}$ for sewage sludge (left) and manure (right). Different colours depict different substrates. Differences in manure type were not accounted in for this analysis. Each dot represents an experiment

of the evidence. Different $\mathrm{N}$ measuring techniques was also a problem for the struvite precipitation studies, which contributed to the decision of not performing quantitative synthesis with respect to removal of $\mathrm{NH}_{4}$ for struvite precipitation.

\section{Review conclusions}

\section{Implications for research}

For struvite precipitation, the quantitative synthesis showed that the maximum efficiency of the process is achieved around $\mathrm{pH}$ 9.5. $\mathrm{Mg}$ to $\mathrm{PO}_{4}$ ratio was found to have a positive effect on removal up to a ratio as high as 4 to 1 . However, dosing $\mathrm{Mg}$ in excess adds additional costs, and it should be noted that relatively high efficiencies were achieved at a ratio as low as 1 to 1 as well. Although the effects of $\mathrm{pH}$ and $\mathrm{Mg}$ to $\mathrm{PO}_{4}$ ratio were clear, the models developed could not accurately predict removal based on these two parameters alone. This could be due to random variation between experiments, but it may also be due to the influence of other process parameters. Although the evidence base for struvite precipitation was deemed too limited to draw conclusions regarding process parameters other than $\mathrm{pH}$ and $\mathrm{Mg}: \mathrm{PO}_{4}$ ratio, it is noted that other parameters may exert an influence on the outcome and as such could be interesting to investigate further. These include total solid content, initial concentrations of reactants, seed crystal additions, reaction time and temperature.
The evidence base for ammonia stripping was considered too small and too heterogenous to be quantitatively synthesised. To ensure comparability for future research, we call on authors to present at least the following parameters when performing experiments on ammonia stripping:

- $\mathrm{pH}$ of the inflow to the stripping process

- Liquid and air flow rates

- Temperature of both the liquid and the air in the inflow

- Concentrations in terms of ammonia or TAN as well as total nitrogen

- Both removal and recovery in the stripping column as well as recovery in the acid scrubber

In order for struvite precipitation and ammonia stripping to be useful technologies in the transition towards a circular economy, it is not enough that the technical processes are efficient (as evaluated in this review). In order to close the nutrient cycle, it is also essential that the products are reused effectively (e.g. as soil amendments) [69]. The effectiveness of the products of struvite precipitation and ammonia stripping (struvite and ammonium sulphate) is currently being addressed in a parallel review [27].

\section{Implications for policy/management}

Our findings suggest that, when performed under the right conditions (i.e. $\mathrm{pH}$ around 9.5 and $\mathrm{Mg}: \mathrm{PO}_{4}$ ratio of 


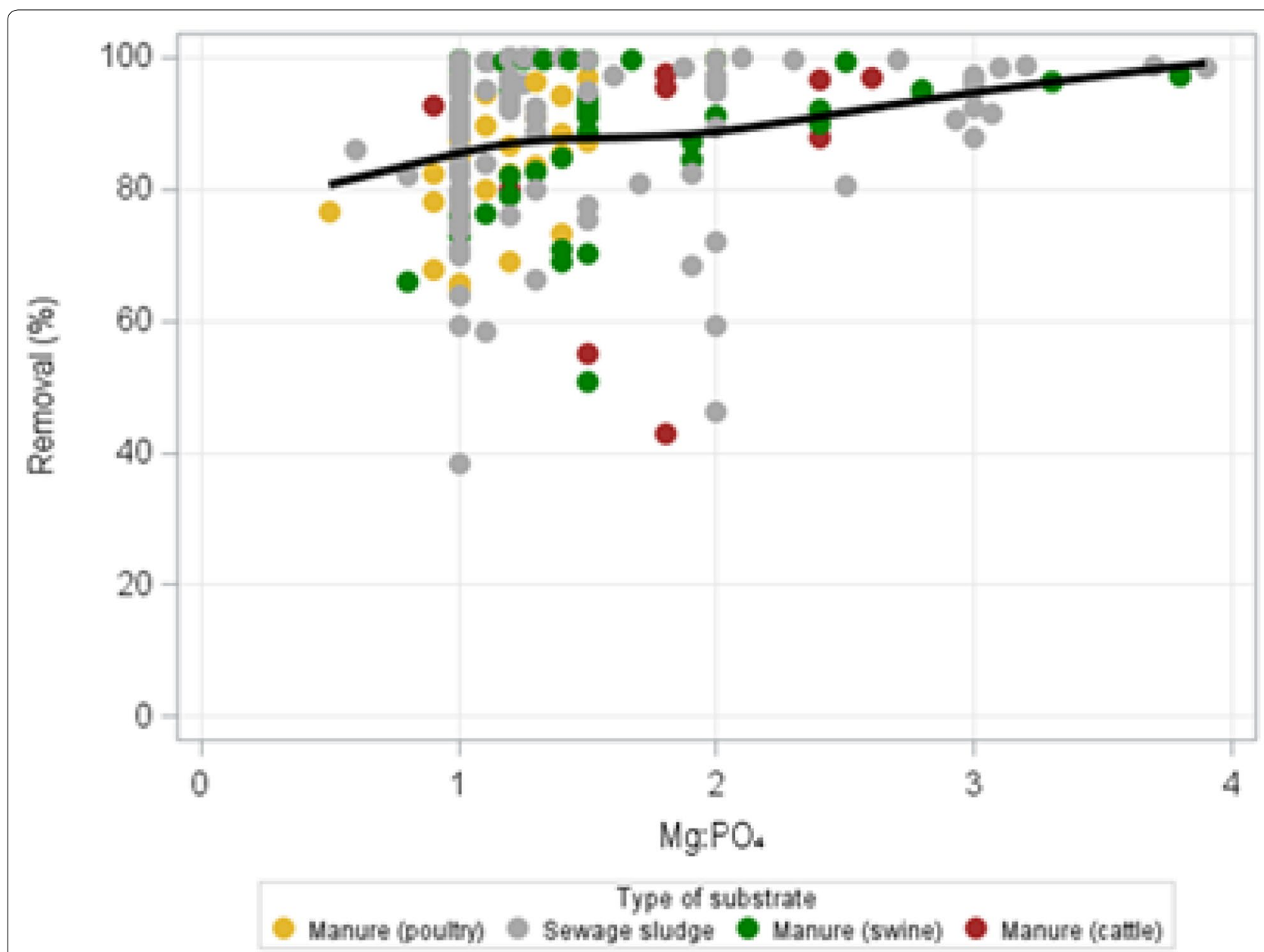

Fig. $10 \mathrm{PO}_{4}-\mathrm{P}$ removal as a function of $\mathrm{Mg}: \mathrm{PO}_{4}$ ratio, all substrates (different substrates are shown, but the variation between different substrates was not taken into account when producing the function). Each dot represents an experiment
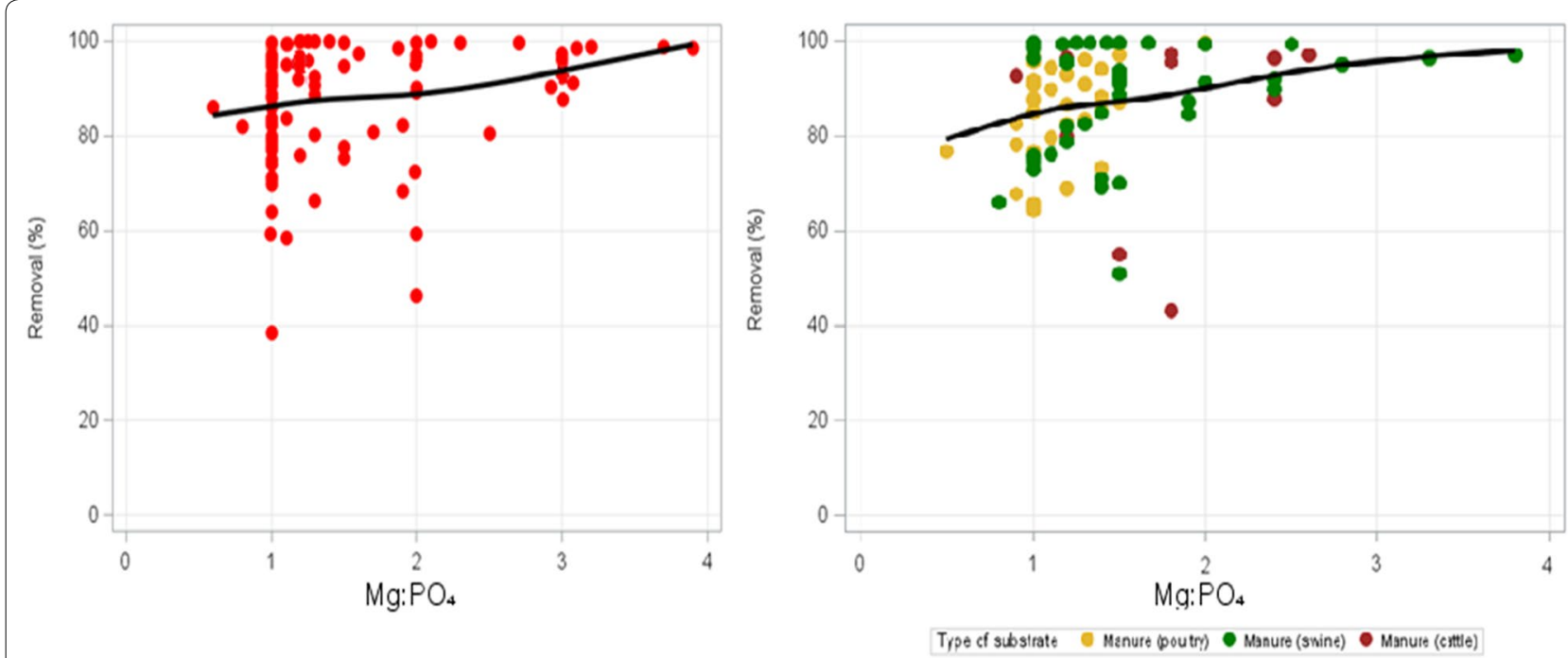

Fig. $11 \mathrm{PO}_{4}-\mathrm{P}$ removal as a function of $\mathrm{Mg}: \mathrm{PO}_{4}$ ratio for sewage sludge (left) and manure (right). Each dot represents an experiment 


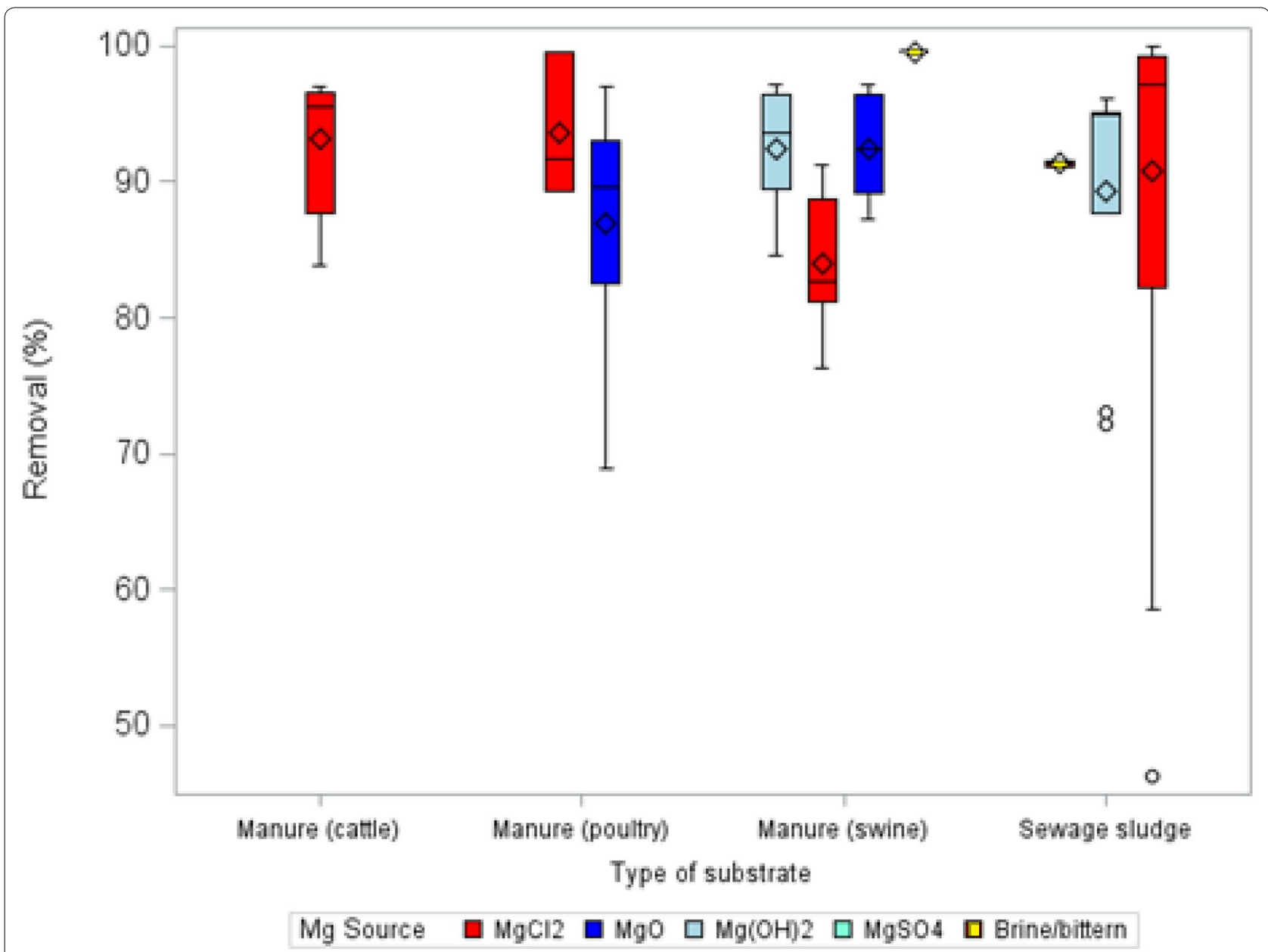

Fig. $12 \mathrm{PO}_{4}-\mathrm{P}$ removal as a function of $\mathrm{Mg}$ source (see legend), divided per substrate

at least 1:1), struvite precipitation is an effective technology for the recovery of nutrients from the liquid phase of anaerobic digestate. The evidence base was limited for ammonia stripping. In a wastewater treatment setting, both struvite precipitation and ammonia stripping could be applied to the liquid phase of digested sewage sludge in order to produce a fertilizer product. In an agricultural setting, both technologies could be applied to the liquid phase of digested manure in order to produce fertilizer products that are easier to transport than manure. Note, however, that the potential yield of the product (struvite or ammonium sulphate) is limited to the amount of nutrients in the liquid phase of the digestate. The present work provides a wider understanding of struvite precipitation and ammonia stripping and the conditions under which these technologies are effective. This work contributes to a knowledge base for the transition to a circular economy, nutrient circularity and food security. 

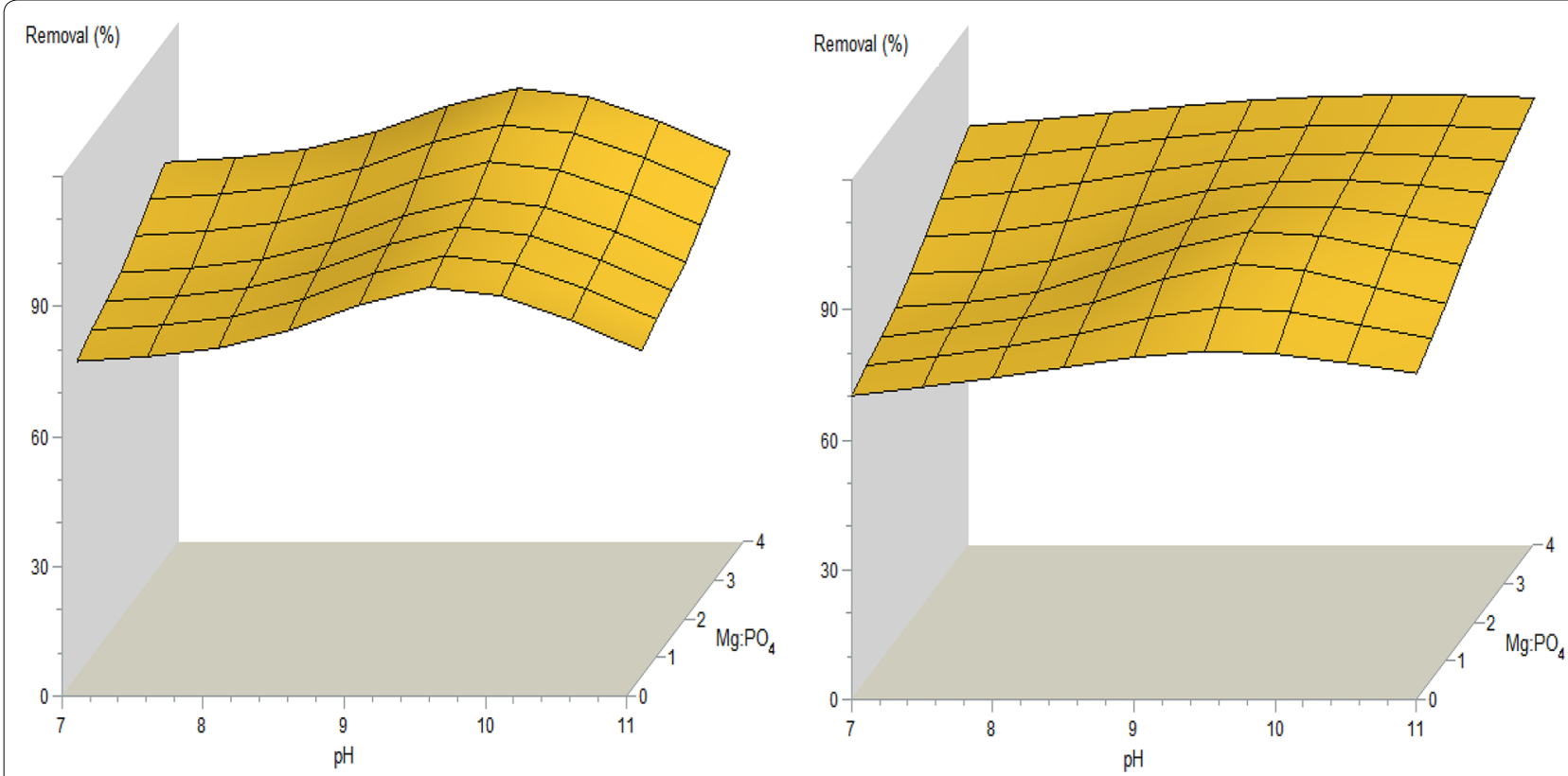

Fig. $13 \mathrm{PO}_{4}-\mathrm{P}$ removal as a function of $\mathrm{pH}$ and $\mathrm{Mg}$ to $\mathrm{PO} 4$ ratio. The additive GAM model is presented on the left, and the thin plate model on the right

Table 4 Location of studies included in the ammonia stripping database

\begin{tabular}{lll}
\hline Continent & Country & $\begin{array}{l}\text { Number } \\
\text { of studies }\end{array}$ \\
\hline Europe & Belgium & 1 \\
& Italy & 2 \\
& Spain & 1 \\
& Switzerland & 2 \\
Asia & China & 2 \\
\hline
\end{tabular}

Table 5 The studies included in the ammonia stripping evidence base

\begin{tabular}{|c|c|c|}
\hline Citation & Substrate & Study scale \\
\hline Boehler et al. (2015) [61] & Sewage sludge, urine & Macro \\
\hline Bolzonella et al. (2018) [62] & $\begin{array}{l}\text { Dairy manure, swine manure } \\
\text { and energy crops } \\
\text { sludge }\end{array}$ & Macro \\
\hline Ghyselbrecht et al. 2018 [63] & $\begin{array}{l}\text { Effluent from potato pro- } \\
\text { cessing }\end{array}$ & Laboratory \\
\hline Ledda et al. (2013) [64] & Swine and cow manure & Medium \\
\hline Shanshan et al. (2016) [65] & Poultry manure & Laboratory \\
\hline Morales et al. (2013) [66] & Sewage sludge, urine & Macro \\
\hline Hidalgo et al. (2016) [67] & Swine manure & Laboratory \\
\hline Li et al. (2016) [68] & Swine manure & Laboratory \\
\hline
\end{tabular}

\section{Supplementary information}

Supplementary information accompanies this paper at https://doi. org/10.1186/s13750-020-00211-X.

\author{
Additional file 1:: ROSES form for systematic review \\ Additional file 2: Search record \\ Additional file 3: List of unobtainable articles \\ Additional file 4: List of excluded articles at full text screening \\ Additional file 5: Critical appraisal of study validity \\ Additional file 6: Data extraction \\ Additional file 7: Narrative tables \\ Additional file 8: Statistical analysis \\ Additional file 9: Meta-analysis of Struvite Precipitation
}

\section{Acknowledgements}

We thank the BONUS Secretariat for their generous funding. We are grateful to Berndt Björlenius, Neal Haddaway, Solveig Johannesdottir, Marta Ksiezniak, Elisabeth Kvarnström, Pawel Osuch, Mikolaj Piniewski and Yina Salamanca for their valuable assistance in various stages of this review process.

\section{Authors' contributions}

$D L$ with BM drafted the first version of the manuscript (and based on a deliverable from Bonus Return project). BM oversaw the review process and provided methodological guidance. DL and MA screened, critically appraised and extracted the data. RH contributed to development of the critical appraisal tool. AG conducted statistical analysis. All authors edited, read and approved the final manuscript. 


\section{Funding}

BONUS RETURN has received funding from BONUS (Art 185), funded jointly by the EU and Formas, A Swedish Research Council for Sustainable Development; Sweden's innovation agency, Vinnova; Academy of Finland; and the National Centre for Research and Development in Poland.

\section{Availability of data and material}

All generated and analysed data are available in the article and/or additional files.

\section{Ethics approval and consent to participate}

Not applicable.

\section{Consent for publication}

Not applicable.

\section{Competing interests}

The authors declare no competing interests.

\section{Author details}

${ }^{1}$ Stockholm Environment Institute, Linnégatan 87D, Stockholm, Sweden.

${ }^{2}$ RISE Research Institutes of Sweden, Ultunaallén 4, Uppsala, Sweden. ${ }^{3}$ Swedish Institute for the Marine Environment, Box 260, 40530 Göteborg, Sweden.

${ }^{4}$ Environmental Engineering Group, Department of Energy and Technology,

Swedish University of Agricultural Sciences, Uppsala, Sweden.

Received: 5 May 2020 Accepted: 30 October 2020

Published online: 11 November 2020

\section{References}

1. Dawson CJ, Hilton J. Fertiliser availability in a resource-limited world: Production and recycling of nitrogen and phosphorus. Food Policy. 2011;36:S14-22

2. Liu J, You L, Amini M, Obersteiner M, Herrero M, Zehnder AJB, Yang H. A high-resolution assessment on global nitrogen flows in cropland. Proc Natl Acad Sci USA. 2010;107(17):8035.

3. Cordell D, White S. Peak phosphorus: clarifying the key issues of a vigorous debate about long-term phosphorus security. Sustainability. 2011;3:2027-49.

4. Cordell D, White S. Life's bottleneck: sustaining the world's phosphorus for a food secure future. Annu Rev Environ Resour. 2014;39(1):161-88.

5. van Dijk KC, Lesschen JP, Oenema O. Phosphorus flows and balances of the European Union Member States. Sci Total Environ. 2016;542:1078-93.

6. Buckwell A, Nadeu E. Nutrient Recovery and Reuse (NRR) in European agriculture: a review of the issues, opportunities, and actions. Brussels: RISE Foundation; 2016.

7. Jones DL, Cross P, Withers PJA, DeLuca TH, Robinson DA, Quilliam RS, Harris IM, Chadwick DR, Edwards-Jones G. REVIEW: nutrient stripping: the global disparity between food security and soil nutrient stocks. J Appl Ecol. 2013;50(4):851-62.

8. Shober AL, Maguire RO. Manure management. In: Flow ESF, editor. Reference module in earth systems and environmental sciences. Amsterdam: Elsevier; 2018

9. McCrackin ML, Gustafsson BG, Hong B, Howarth RW, Humborg C, Savchuk OP, Svanbäck A, Swaney DP. Opportunities to reduce nutrient inputs to the Baltic Sea by improving manure use efficiency in agriculture. Reg Environ Change. 2018;18(6):1843-54.

10. Harder R, Wielemaker R, Molander S, Öberg G. Reframing human excreta management as part of food and farming systems. Water Res. 2020;175:115601.

11. Mateo-Sagasta J, Raschid-Sally L, Thebo A. Global wastewater and sludge production, treatment and use. In: Drechsel P, Qadir M, Wichelns D, editors. Wastewater. Dordrecht: Springer; 2015.

12. Yeoman S, Stephenson T, Lester J, Perry R. The removal of phosphorus during wastewater treatment: a review. Environ Pollut. 1988;49:183-233.

13. Peccia J, Westerhoff P. We should expect more out of our sewage sludge. Environ Sci Technol. 2015;49:8271-6.
14. Rockström J, Steffen W, Noone K, Persson Å, Chapin lii FS, Lambin EF, Lenton TM, Scheffer M, Folke C, Schellnhuber HJ, et al. A safe operating space for humanity. Nature. 2009;461:472.

15. Steffen W, Richardson K, Rockström J, Cornell SE, Fetzer I, Bennett EM, Biggs R, Carpenter SR, de Vries W, de Wit CA, et al. Planetary boundaries: guiding human development on a changing planet. Science. 2015;347(6223):1259855.

16. Haddaway NR, Johannesdottir SL, Piniewski M, Macura B. What ecotechnologies exist for recycling carbon and nutrients from domestic wastewater? A systematic map protocol. Environ Evid. 2019;8:1.

17. Johannesdottir S, Macura B, McConville J, Lorick D, Haddaway N, Karczmarczyk A, Ek F, Piniewski M, Księżniak M, Osuch P: What evidence exists on ecotechnologies for recycling carbon and nutrients from domestic wastewater? A systematic map (unpublished manuscript, submitted to Environmental evidence). In. Edited by SEl Ra; 2020.

18. Macura B, Piniewski M, Księżniak M, Osuch P, Haddaway N, Ek F, Andersson K, Tattari S. Effectiveness of ecotechnologies in agriculture for the recovery and reuse of carbon and nutrients in the Baltic and boreotemperate regions: a systematic map. Environ Evid. 2019;8:1-18.

19. Rahman MM, Salleh MAM, Rashid U, Ahsan A, Hossain MM, Ra CS. Production of slow release crystal fertilizer from wastewaters through struvite crystallization - a review. Arab J Chem. 2014;7(1):139-55.

20. Muhmood A, Lu J, Dong R, Wu S. Formation of struvite from agricultural wastewaters and its reuse on farmlands: status and hindrances to closing the nutrient loop. J Environ Manage. 2019;230:1-13.

21. Carey DE, Yang Y, McNamara PJ, Mayer BK. Recovery of agricultural nutrients from biorefineries. Biores Technol. 2016;215:186-98.

22. Kinidi L, Tan IAW, Abdul Wahab NB, Tamrin KFB, Hipolito CN, Salleh SF. Recent development in ammonia stripping process for industrial wastewater treatment. Int J Chem Eng. 2018;2018:14.

23. Venkiteshwaran K, McNamara PJ, Mayer BK. Meta-analysis of non-reactive phosphorus in water, wastewater, and sludge, and strategies to convert it for enhanced phosphorus removal and recovery. Sci Total Environ. 2018;644:661-74

24. Ma J, Kennedy N, Yorgey G, Frear C. Review of emerging nutrient recovery technologies for farm-based anaerobic digesters and other renewable energy systems. Pullman: Washington State University; 2013.

25. Collaboration for environmental evidence: guidelines and standards for evidence synthesis in environmental management. In: Pullin A, Frampton G, Livoreil B, Petrokofsky G, editors Version 5.0. 2018.

26. Haddaway NR, Macura B, Whaley P, Pullin AS. ROSES for systematic review reports. Version 10. 2017. https://doi.org/10.6084/m9.figshare.5897272.v4.

27. Macura B, Johannesdottir SL, Piniewski M, Haddaway NR, Kvarnström E. Effectiveness of ecotechnologies for recovery of nitrogen and phosphorus from anaerobic digestate and effectiveness of the recovery products as fertilisers: a systematic review protocol. Environ Evid. 2019;8(1):29.

28. Harzing AW: Publish or Perish, available from https://harzing.com/resou rces/publish-or-perish. 2007.

29. Thomas J, Brunton J, Graziosi S: EPPI-Reviewer 4.0: software for research synthesis. EPPI-Centre Software. . In., 4.0 edn. London: Social Science Research Unit, Institute of Education, University of London.; 2010.

30. Hastie T, Tibshirani R. Generalized additive model. Boca Raton: Chapman and Hall/CRC; 1990.

31. Haddaway N, Macura B, Whaley P, Pullin A: ROSES flow diagram for systematic reviews. Version 1.0. 2017

32. Bohdziewicz J, Kuglarz M. Treatment of post-digestion liquors with the application of struvite precipitation and reverse osmosis. Desalin Water Treatment. 2013;51(1-3):366-73.

33. Connan R, Dabert P, Moya-Espinosa M, Bridoux G, Béline F, Magrí A. Coupling of partial nitritation and anammox in two- and one-stage systems: process operation, $\mathrm{N}_{2} \mathrm{O}$ emission and microbial community. J Clean Product. 2018;203:559-73.

34. Garcia-Belinchón C. Struvite recovery: pilot-scale results and economic assessment of different scenarios. Water Pract Technol. 2013;8:119-30.

35. Huang H, Liu J, Ding L. Recovery of phosphate and ammonia nitrogen from the anaerobic digestion supernatant of activated sludge by chemical precipitation. J Clean Product. 2015;102:437-46.

36. Jia G, Zhang H, Krampe J, Muster T, Gao B, Zhu N, Jin B. Applying a chemical equilibrium model for optimizing struvite precipitation for ammonium recovery from anaerobic digester effluent. J Clean Product. 2017;147:297-305. 
37. Kalam S. A pilot scale study of combining struvite precipitation with UniBAR-anammox process as a sustainable unified solution for managing nutrients in centrate. Vancouver: University of British Columbia; 2015.

38. Karabegovic L, Uldal M, Werker A, Morgan-Sagastume F. Phosphorus recovery potential from a waste stream with high organic and nutrient contents via struvite precipitation. Environ Technol. 2013;34(5-8):871-83.

39. Lahav O, Telzhensky M, Zewuhn A, Gendel Y, Gerth J, Calmano W, Birnhack $L$. Struvite recovery from municipal-wastewater sludge centrifuge supernatant using seawater NF concentrate as a cheap Mg(II) source. Sep Purif Technol. 2013;108:103-10.

40. Muhmood A, Lu J, Kadam R, Dong R, Guo J, Wu S. Biochar seeding promotes struvite formation, but accelerates heavy metal accumulation. Sci Total Environ. 2019;652:623-32.

41. Qin Y, Hu S. Study on release characteristics and recovery of nitrogen and phosphorus during the anaerobic fermentation of excess sludge. IOP Conf Ser Earth Environ Sci. 2018;108:042018.

42. Sharp R, Vadiveloo E, Fergen R, Moncholi M, Pitt P, Wankmuller D, Latimer R. A theoretical and practical evaluation of struvite control and recovery. Water Environ Res. 2013;85(8):675-86.

43. Xavier LD, Cammarota MC, Yokoyama L, Volschan Junior I. Study of the recovery of phosphorus from struvite precipitation in supernatant line from anaerobic digesters of sludge. Water Sci Technol. 2014;69(7):1546-51.

44. Zheng W, Li X-M. High-quality magnesium ammonium phosphate produced from digested sewage sludge by adsorption. Fresenius Environ Bull. 2014;23:756-62.

45. Lee $\mathrm{E}$, Oh M, Yang S-H, Yoon T. Struvite crystallization of anaerobic digestive fluid of swine manure containing highly concentrated nitrogen. Asian-Austral J Anim Sci. 2015;28:1053.

46. Castro L, Vecino-Gutierrez K, Díaz-Moyano L, Jaimes-Estévez J, EscalanteHernández $\mathrm{H}$. Lighting the anaerobic digestion process in rural areas: obtainment of struvite from bovine manure digestate. Revista Colombiana de Biotecnología. 2018;20:78-88.

47. Farrow C, Crolla A, Kinsley C, McBean E. Ammonia removal from poultry manure leachate via struvite precipitation: a strategy for more efficient anaerobic digestion. Int J Environ Technol Manage. 2017;20:87.

48. Huang $H$, Chen $Y$, Jiang $Y$, Ding L. Treatment of swine wastewater combined with $\mathrm{MgO}$-saponification wastewater by struvite precipitation technology. Chem Eng J. 2014;254:418-25.

49. Jiang Y, Pu X, Zheng D, Zhu T, Wang S, Deng L, Wang W. Cultivation of lipid-producing microalgae in struvite-precipitated liquid digestate for biodiesel production. Biotechnol Biofuels. 2018;11:101.

50. Kim D, Min K, Yu M, Lee K, Kweon J. Use of concentrate water from seawater desalination plant as magnesium sources for struvite formation by using anaerobically digested effluent of swine wastewater. Desalin Water Treat. 2016;57:1-7.

51. Lin H, Lin Y, Wang D, Pang Y, Zhang F, Tan S. Ammonium removal from digested effluent of swine wastewater by using solid residue from magnesium-hydroxide flue gas desulfurization process. J Ind Eng Chem. 2018;58:148-54.

52. Muhmood A, Wu S, Lu J, Ajmal Z, Luo H, Dong R. Nutrient recovery from anaerobically digested chicken slurry via struvite: Performance optimization and interactions with heavy metals and pathogens. Sci Total Environ. 2018;635:1-9.

53. Shen $Y$, Ye Z-L, Ye X, Wu J, Chen S. Phosphorus recovery from swine wastewater by struvite precipitation: compositions and heavy metals in the precipitates. Desalin Water Treat. 2016;57(22):10361-9.

54. Wang J, Ye X, Zhang Z, Ye Z-L, Chen S. Selection of cost-effective magnesium sources for fluidized struvite crystallization. J Environ Sci. 2018;70:144-53

55. Zhang T, Fang C, Li P. Application of struvite process for nutrient recovery from anaerobic digesters of livestock wastewater. Environ Prot Eng. 2014;40:29-42.
56. Zhang H, Gong W, Luo X, Xie B, Li G, Liang H. Obtaining high-purity struvite from anaerobically digested wastewater: effects of $\mathrm{pH}, \mathrm{Mg} / \mathrm{P}$, and $\mathrm{Ca}^{2+}$ interactions. Environ Eng Sci. 2018;36:102-13.

57. Balaguer-Barbosa M: Recovery of Nutrients from Anaerobically Digested Enhanced Biological Phosphorus Removal (EBPR) Sludge through Struvite Precipitation. University of South Florida; 2018

58. Liu Y, Qu H. Interplay of digester supernatant composition and operating pH on impacting the struvite particulate properties. J Environ Chem Eng. 2017:5(4):3949-55

59. Cerrillo M, Palatsi J, Comas J, Vicens J, Bonmatí A. Struvite precipitation as a technology to be integrated in a manure anaerobic digestion treatment plant - removal efficiency, crystal characterization and agricultural assessment. J Chem Technol Biotechnol. 2015;90(6):1135-43.

60. Crutchik D, Morales N, Vázquez-Padín JR, Garrido JM. Enhancement of struvite pellets crystallization in a full-scale plant using an industrial grade magnesium product. Water Sci Technol. 2017;75(3-4):609-18.

61. Boehler MA, Heisele A, Seyfried A, Grömping M, Siegrist $H$. $\left(\mathrm{NH}_{4}\right)_{2} \mathrm{SO}_{4}$ recovery from liquid side streams. Environ Sci Pollut Res. 2015;22(10):7295-305.

62. Bolzonella D, Fatone F, Gottardo M, Frison N. Nutrients recovery from anaerobic digestate of agro-waste: techno-economic assessment of full scale applications. J Environ Manage. 2018;216:111-9.

63. Ghyselbrecht K, Monballiu A, Somers MH, Sigurnjak I, Meers E, Appels L, Meesschaert B. Stripping and scrubbing of ammonium using common fractionating columns to prove ammonium inhibition during anaerobic digestion. Int J Energy Environ Eng. 2018;9(4):447-55.

64. Ledda C, Schievano A, Salati S, Adani F. Nitrogen and water recovery from animal slurries by a new integrated ultrafiltration, reverse osmosis and cold stripping process: a case study. Water Res. 2013;47(16):6157-66.

65. Shanshan M, Haifeng L, Zhang Y, Li B, Taili D, Dongming Z. Nitrogen and biomass recovery from low carbon to nitrogen ratio wastewater by combing air stripping and microalgae cultivation. J Residu Sci Technol. 2016:13:S23-31.

66. Morales N, Boehler M, Buettner S, Liebi C, Siegrist H. Recovery of N and P from urine by struvite precipitation followed by combined stripping with digester sludge liquid at full scale. Water. 2013;5:1262-78.

67. Hidalgo D, Corona F, Martín-Marroquín JM, del Álamo J, Aguado A. Resource recovery from anaerobic digestate: struvite crystallisation versus ammonia stripping. Desalin Water Treat. 2016;57(6):2626-32.

68. Li X, Guo J, Dong R, Ahring BK, Zhang W. Properties of plant nutrient: Comparison of two nutrient recovery techniques using liquid fraction of digestate from anaerobic digester treating pig manure. Sci Total Environ. 2016;544:774-81.

69. Barquet K, Järnberg L, Rosemarin A, Macura B. Identifying barriers and opportunities for a circular phosphorus economy in the Baltic Sea region. Water Res. 2020;171:115433

\section{Publisher's Note}

Springer Nature remains neutral with regard to jurisdictional claims in published maps and institutional affiliations.

Ready to submit your research? Choose BMC and benefit from:

- fast, convenient online submission

- thorough peer review by experienced researchers in your field

- rapid publication on acceptance

- support for research data, including large and complex data types

- gold Open Access which fosters wider collaboration and increased citations

- maximum visibility for your research: over 100M website views per year

At BMC, research is always in progress.

Learn more biomedcentral.com/submissions 